\title{
A expansão da jurisdição da Corte Interamericana de Direitos Humanos através de opiniões consultivas
}

\section{The Expansion of the Inter-American Court of Human Rights' Jurisdiction Through Advisory Opinions}

\author{
Élargissement de la compétence de la Cour \\ interaméricaine des droits de l'homme \\ par le biais d'opinions consultatifs
}

\section{Lucas Carlos Lima* Lucas Mendes Felippe**}

\begin{abstract}
SUMÁRIO: I. Introdução: tensões na função consultiva da Corte Interamericana. II. Expansão material nas opiniões consultivas da CtIDH: business as usual? III. A expansão da jurisdição contenciosa através da jurisdição consultiva: problemas recentes. IV. Pontos de força, riscos e consequências da expansão da Corte em via consultiva. V. Conclusões. VI. Bibliografia.
\end{abstract}

* Universidade Federal de Minas Gerais, Brasil; ORCID ID: https: / orcid.org/0000-00028643-6547,1clima@ufmg.br.

** Universidade Federal de Minas Gerais, Brasil; ORCID ID: https: //orcid.org/0000-00030208-1716. 
ReSUMO: Ao interpretar a Convenção Americana sobre Direitos Humanos através de opiniões consultivas, a Corte Interamericana de Direitos Humanos (CtIDH) em diversas ocasiões impactou também sua função contenciosa. Em algumas opiniões recentes, sustenta-se que a Corte Interamericana expandiu o âmbito de sua jurisdição contenciosa. Nesse artigo, são analisadas as técnicas interpretativas empregadas pela CtIDH para, através da via consultiva, aumentar o alcance de sua jurisdição contenciosa. Será realizada uma análise tanto das decisões da Corte bem como da literatura especializada e do posicionamento de alguns Estados em relação à Corte. Num contexto de resistência e contestação de cortes internacionais, sustenta-se que a atividade de expansão da jurisdição da Corte pode possuir efeitos positivos e negativos em relação à sua autoridade e legitimidade, mas que uma maior cautela em relação à expansão de sua jurisdição e ao uso do artigo 26 para circunscrever o consentimento dos Estados evitaria quaisquer efeitos negativos.

Palavras-chave: Corte Interamericana de Direitos Humanos, opiniões consultivas, expansão da jurisdição, autoridade e legitimidade de cortes internacionais.

ABSTRACT: While interpreting the American Convention on Human Rights through consultative opinions, the Inter-American Court of Human Rights (IACtHR) has also impacted its adjudicatory function on several occasions. In some recent opinions, it is claimed that the Inter-American Court has expanded the scope of its contentious jurisdiction. In this article, we analyze the interpretative techniques employed by the IACtHR, through advisory opinions, to increase the scope of its adjudicatory jurisdiction. An analysis will be made of both the Court's decisions as well as the specialized literature and the position of some States in relation to the Court. In a context of resistance and contestation of international courts, it is stated that the activity of expanding the jurisdiction of the Court may have positive and negative effects in relation to its authority and legitimacy, but that greater caution in relation to the expansion of its jurisdiction and the utilization of article 26 to circumscribe the consent of States would avoid any negative effects.

Key words: Inter-American Court of Human Rights, advisory opinions, jurisdiction expansion, authority and legitimacy of international courts.

RÉSUMÉ: En interprétant la Convention américaine relative aux droits de l'homme par le biais d'avis consultatifs, la Cour interaméricaine des droits de l'homme (CtIDH) a également eu à plusieurs reprises un impact sur sa fonction contentieuse. Dans certains avis récents, on considère que la Cour interaméricaine a élargi la portée de sa compétence contentieuse. Dans cet article, on analyse les techniques d'interprétation employée par la CtIDH pour que, à travers des avis consultatifs, sa portée de la compétence contentieuse soit élargiee. On fera une analyse des décisions de la Cour, et aussi de la littérature spécialisée et du positionnement de certains États par rapport à la Cour. Dans un contexte de résistance et de contestation des tribunaux internationaux, il est soutenu que l'activité d'élargissement de la compétence de la Cour peut avoir des effets positifs et négatifs en ce qui concerne son autorité et sa légitimité, mais une plus grande prudence quant à l'élargissement de sa compétence et l'utilisation de l'article 26 pour circonscrire le consentement des États éviterait tout effet négatif.

Mots-clés: Cour interaméricaine des droits de l'homme, avis consultatifs, extension de la compétence, autorité et légitimité des cours internationales. 


\section{INTRODUÇÃO: TENSÕES NA FUNÇÃO CONSULTIVA \\ DA CORTE INTERAMERICANA}

A tendência dos Estados membros do Sistema Interamericano de Direitos Humanos ("SIDH" ou "Sistema") de requisitar opiniões consultivas à Corte Interamericana de Direitos Humanos (“CtIDH” ou "Corte”) em relação aos direitos protegidos na Convenção Americana sobre Direitos Humanos ("CADH" ou "Convenção") gera efeitos jurídicos e de política judiciária que impactam a jurisdição contenciosa da Corte. ${ }^{1}$ Em suma, os direitos desenvolvidos e interpretados pela Corte em via consultiva são posteriormente aplicados na jurisdição contenciosa. Se, por um lado, é um direito dos Estados "consultar a Corte sobre a interpretação [da] Convenção ou de outros tratados concernentes à proteção dos direitos humanos nos Estados americanos", ${ }^{2}$ por outro, a competência da Corte está limitada a "conhecer de qualquer caso relativo à interpretação e aplicação das disposições desta Convenção que lhe seja submetido". ${ }^{3}$ Parece existir uma tensão entre os direitos que a Corte reconhece no âmbito de sua jurisdição consultiva e os impactos deste reconhecimento na posterior aplicação contenciosa da Corte.

Desde sua criação, cortes e tribunais internacionais enfrentam o problema de produção normativa através de decisões judiciais. ${ }^{4}$ Com base na teo-

1 No momento de submissão desse artigo, os últimos oito pareceres consultivos emitidos pela Corte Interamericana foram solicitados por Estados (OC-18/03 a OC-25/18). Desde o início das atividades do órgão jurisdicional, os Estados Partes da CADH foram os maiores propulsores da competência consultiva, os quais solicitaram por 22 vezes a emissão de pareceres, ao passo que se contabilizam 11 pedidos originados da Comissão Interamericana de Direitos Humanos e um do Secretário Geral da OEA. Encontram-se em deliberação duas solicitações da Colômbia e duas da CIDH, todas apresentadas em 2019.

2 Artigo 64 da Convenção Americana sobre Direitos Humanos.

3 Artigo 62 da Convenção Americana sobre Direitos Humanos.

4 O problema foi classicamente analisado por Lauterpacht, Hersch, The Development of International Law by the International Court, Londres, Stevens \& Sons, Ltd.; Nova Iorque, Frederick A. Prager, 1958, embora haja ampla bibliografia cotejando a questão. Referencia-se aqui: Pellet, Alain, "Decisions of the ICJ as Sources of International Law?", Gaetano Morelli Lectures Series, vol. 2, 2018, pp. 7-61; Tams, Christian J., "The Development of International Law by the International Court of Justice”, Gaetano Morelli Lectures Series, vol. 2, 2018, pp. 63-106; Guillaume, Gilbert, “The Use of Precedent by International Judges and Arbitrators”, Journal 
ria clássica de produção normativa do ordenamento internacional, ${ }^{5}$ o papel relegado aos órgãos jurisdicionais seria o de aplicação das normas jurídicas existentes produzidas por outros sujeitos do ordenamento internacional, nomeadamente os Estados. A partir do momento em que instâncias judiciais começaram a expandir o alcance de determinadas normas, desenvolvendo o direito internacional, problemas começaram a emergir em relação aos limites e poderes da constelação judicial internacional. Hersch Lauterpacht admoestava, já em 1958, que juízes podem ser "ao mesmo tempo dóceis servidores do passado e tiranos do futuro". ${ }^{6} \mathrm{O}$ fenômeno foi descrito sob diversas alcunhas como international judicial lawmaking ou international judicial activism. Embora a questão seja uma realidade desde a metade do século XX, o problema parece se agudizar na medida em que cortes e tribunais internacionais utilizam destes expedientes para expandir a própria jurisdição, ${ }^{7}$ alargando o alcance de seus poderes e de situações que estejam aptas a decidir.

O problema não se faz ausente no âmbito da jurisprudência da Corte Interamericana. Como uma corte cuja vocação hermenêutica é a de amálga-

of International Dispute Settlement, vol. 2, 2011, pp. 5-23; De Brabandere, Eric, "The Use of Precedent and External Case Law by the International Court of Justice and the International Tribunal for the Law of the Sea", The Law and Practice of International Courts and Tribunals, vol. 15, 2016, pp. 24-55. Na doutrina brasileira, o problema foi afrontado por Cançado Trindade, Antônio Augusto, "Os tribunais internacionais contemporâneos e a busca da realização do ideal da justiça internacional”, Revista da Faculdade de Direito da UFMG, vol. 57, 2010, pp. 37 68, e Lima, Lucas Carlos, “As decisões da Corte Internacional de Justiça como elemento de desenvolvimento do direito internacional”, em Dal Ri Junior, Arno e Moura, Aline Beltrame de (orgs.), Jurisdição internacional: interação, fragmentação, obrigatoriedade, Ijuí, Unijuí, 2014.

5 Sobre a questão, ver Pellet, Alain e Muller, Daniel, “Article 38”, em Zimmermann, Andreas et al. (orgs.), The Statute of the International Court of Justice: A Commentary, Oxford, Oxford University Press, 2012; Pinto, Mónica, Las fuentes del derecho internacional en la era de la globalización, Buenos Aires, Eudeba, 2010; Thirlway, Hugh, The Sources of International Law, 2a. ed., Oxford, Oxford University Press, 2019; D’Aspremont, Jean, Formalism and the Sources of International Law: A Theory of the Ascertainment of Legal Rules, Oxford, Oxford University Press, 2011. Em particular sobre a questão dos princípios como fontes e sua relação com decisões judiciais, ver Bonafé, Beatrice I. e Palchetti, Paolo, "Relying on General Principles in International Law”, em Brölmann, Catherine e Radi, Yannick, Research Handbook on the Theory and Practice of International Lawmaking, Cheltenham, Elgar Publishing, 2016.

6 Lauterpacht, Hersch, op. cit., p. 21.

7 Sobre essa questão, principalmente em reações à expansão realizada em tribunais internacionais, conferir Treves, Tullio, "The Expansion of International Law. General Course on Public International Law”, Collected Courses of the Hague Academy of International Law, vol. 398, 2015, pp. 329 e ss. 
Esta revista forma parte del acervo de la Biblioteca Jurídica Virtual del Instituto de Investigaciones Jurídicas de la UNAM

ma de direitos humanos, categoria de direitos historicamente significativa, é esperado determinado posicionamento vanguardista. ${ }^{8}$ Em diversas ocasiões a Corte foi responsável por consolidar a interpretação pro persona, dando significado aos direitos que é chamada a aplicar de acordo com a Convenção Americana. ${ }^{9}$ Atividade típica de cortes de direitos humanos, tais técnicas interpretativas de cunho teleológico ou evolutivo foram objeto de análise da ciência jurídica. ${ }^{10}$ Contudo, um problema emerge quando as técnicas utilizadas por uma corte servem não unicamente para expandir o significado dos direitos que é estatutariamente chamada a proteger, mas também para expandir a jurisdição da própria Corte, interferindo nas competências e nas balizas do que os Estados lhe atribuíram para decidir. A Corte Internacional de Justiça (CIJ) já observou que a "jurisdição é sempre baseada no consenti-

8 Para um tour d'horizon sobre a questão, ver Cassese, Antonio, I diritti umani nel mondo contemporaneo, Roma, Laterza, 1988; Costa, Pietro, "Dai diritti naturali ai diritti umani: episodi di retorica universalistica”, em Meccarelli, Massimo et al. (orgs.), Il lato oscuro dei diritti umani, Madrid, Universidad Carlos III de Madrid, 2014; Gordon Lauren, Paul, “The Foundations of Justice and Human Rights in Early Legal Texts and Thought”, em Shelton, Dinah, The Foundations of Justice and Human Rights in Early Legal Texts and Thought, Oxford, Oxford University Press, 2013, e, de maneira geral, Hunt, Lynn, Inventing Human Rights: A History, Nova Iorque, W.W. Norton \& Company, 2008.

9 Ver nesse sentido: Lixinski, Lucas, "Treaty Interpretation by the Inter-American Court of Human Rights: Expansionism at the Service of the Unity of International Law”, European Journal of International Law, vol. 21, 2010, pp. 585-604; Burgorgue-Larsen, Laurence, “«Decompartmentalization»: The Key Technique for Interpreting Regional Human Rights Treaties”, International Journal of Constitutional Law, vol. 16, 2018, pp. 187-213; Burgorgue-Larsen, Laurence, "El contexto, las técnicas y las consecuencias de la interpretación de la Convención Americana de los Derechos Humanos", Estudios Constitucionales, ano 12, núm. 1, 2014, pp. 105-161; Killander, Magnus, "Interpreting Regional Human Rights Treaties”, Revista Sur, vol. 13, 2010, pp. 149-175; Huneeus, Alexandra Valeria e Madsen, Mikael Rask, "Between Universalism and Regional Law and Politics: A Comparative History of the American, European, and African Human Rights Systems", International Journal of Constitutional Law, vol. 16, 2018, pp. 136-160.

10 Também nesse sentido, Neuman, Gerald L., "Import, Export and Regional Consent in the Inter-American Court of Human Rights”, European Journal of International Law, vol. 19, 2008, pp. 101-123; Vives, Francisco Pascual, "Consenso e interpretación evolutiva de los tratados regionales de derechos humanos”, Revista Española de Derecho Internacional, vol. LXVI, 2014, pp. 113-153; Vanneste, Frédéric, “Interpréter la Convention européenne des droits de l'homme et la Convention américaine des droits de l'homme: comment réconcilier les pratiques divergentes avec la théorie générale”, Revue québécoise de droit international, 2016, pp. 81-95. 
mento das partes"11 assim como foi bem pontuado academicamente que "é um truísmo que a jurisdição judicial internacional é baseada no e deriva do consentimento dos Estados". ${ }^{12}$ A expansão da jurisdição da Corte Interamericana via opinião consultiva pode possuir diferentes impactos na autoridade e na legitimidade de uma corte internacional.

Como ocorre em outros tribunais internacionais, embora não sejam obrigatórias, as opiniões consultivas da Corte Interamericana tendem a ser seguidas posteriormente pelo órgão jurisdicional, sobretudo quando realiza a expansão de sua competência - situação que ocorre desde o seu primeiro parecer-.${ }^{13}$ Por exemplo, não raras vezes a Corte se pronunciou sobre questões concernentes ao funcionamento da Comissão Interamericana e da própria Corte, bem como sobre o conteúdo de determinados direitos prescritos na CADH. Por consequência, sua produção consultiva possui efeitos na jurisdição contenciosa. O que se busca no presente artigo, todavia, é apontar como a CtIDH alargou substancialmente sua competência contenciosa em dois pareceres consultivos, de números 22 e 23, de 2016 e 2017, respectivamente.

A questão analisada é dúplice. Em primeiro lugar, busca-se compreender e analisar as técnicas interpretativas empregadas pela Corte Interamericana de Direitos Humanos para, através da via consultiva, aumentar o alcance de sua jurisdição contenciosa. A segunda questão afrontada são os potenciais

11 Do original: "Under the Court's Statute that jurisdiction is always based on the consent of the parties". Corte Internacional de Justiça, Armed Activities on the Territory of the Congo (New Application: 2002) (Democratic Republic of the Congo v. Rwanda), Jurisdiction and Admissibility, Judgment, I.C.J. Reports 200, p. 32, para. 64.

12 Thirlway, Hugh, "The Law and Procedure of the International Court of Justice 19601989: Part Nine”, British Yearbook of International Law, vol. 69, 1998, pp. 1 e 4.

13 Já na primeira opinião, OC-1/82, a Corte declarou que o artigo 64.1 da CADH, que estabelece que a Corte pode interpretar, em sede consultiva, a própria Convenção ou "outros tratados concernentes à proteção dos direitos humanos”, refere-se a qualquer outro tratado firmado por membros da OEA que tenha qualquer disposição concernente à proteção dos direitos humanos, ainda que esse não seja o objetivo principal ou de todo o tratado (paras. 32 e ss.). Por sua vez, na OC-10/89, além da própria Convenção Americana, estabeleceu a possibilidade de interpretar a Declaração Americana de Direitos e Deveres do Homem. Em seguintes a Corte também se permitiu interpretar a Carta da OEA (OC-18/03, para. 57) ou reservas de Estados americanos a tratados (OC-2/82) e, na interpretação de normas internas (artigo 64.2), abarcar leis e normas constitucionais vigentes, projetos de reformas a leis ou normas constitucionais (OC-4/84 e OC-12/91). Também com base nessa interpretação permitiu-se, por exemplo, analisar a Convenção de Viena sobre Relações Consulares na OC-16/99. 
impactos deste exercício à autoridade e legitimidade da Corte Interamericana. Para responder a esses dois questionamentos, será realizada uma análise tanto das decisões da Corte bem como da literatura especializada e do posicionamento de alguns Estados em relação à Corte. Num contexto de resistência e contestação de cortes internacionais, ${ }^{14}$ sustenta-se que a atividade de expansão da jurisdição da Corte pode possuir efeitos positivos e negativos em relação à sua autoridade e legitimidade, mas que uma maior cautela em relação à expansão de sua jurisdição e ao uso do artigo 26 para circunscrever o consentimento dos Estados evitaria quaisquer efeitos negativos.

$\mathrm{O}$ artigo estrutura-se da seguinte forma. Na primeira seção analisa-se a prática anterior de expansão da CtIDH para demonstrar as técnicas utilizadas pela Corte para expandir a interpretação da CADH. Na segunda seção, verifica-se de que maneira a CtIDH expandiu sua jurisdição nas recentes opiniões consultivas e demonstra-se de como essa expansão representa um evitar do consentimento dos Estados para sua jurisdição, em análise das dissidências exibidas no caso Comunidades Indígenas Miembros de la Asociación Lhaka Honhat (Nuestra Tierra) vs. Argentina. Na terceira sessão exploram-se alguns potenciais pontos negativos e positivos para esse exercício por parte da Corte. Nas considerações finais, defende-se maior cautela por parte da Corte Interamericana em relação a interpretação do artigo 26.

\section{EXPANSÃO MATERIAL NAS OPINIÕES CONSULTIVAS}

DA CTIDH: BUSINESS AS USUAL?

A utilização recente da função consultiva da Corte Interamericana de Direitos Humanos para expansão da jurisdição contenciosa contrasta com sua prática anterior. Nesta seção, demonstraremos como a Corte buscou traçar

14 Madsen, Mikael Rask et al., "Backlash against International Courts: Explaining the Forms and Patterns of Resistance to International Courts”, International Journal of Law in Context, núm. especial 2, 2018, pp. 197-220. Ver, nesse sentido: Grossman, Nienke et al. (eds.), Legitimacy and International Courts, Cambridge, Cambridge University Press, 2018; Howse, Robert et al. (eds.), The Legitimacy of International Trade Courts and Tribunals, Cambridge, Cambridge University Press, 2018; Alter, Karen J. et al. (eds.), International Court Authority, Oxford, Oxford University Press, 2018; Von Bogdandy, Armin e Venzke, Ingo, InWhose Name?: A Public Law Theory of International Adjudication, Oxford, Oxford University Press, 2014. 
limites à sua própria jurisdição consultiva, de modo a não interferir em sua jurisdição contenciosa. Demonstraremos como a expansão de direitos materiais ocorria, antes das OCs 22 e 23, com o uso de técnicas interpretativas que não impactavam amplamente nos contornos jurisdicionais contenciosos.

A Corte Interamericana possui a competência consultiva com maior emissão de pareceres, em comparação com os demais sistemas regionais de proteção de direitos humanos, ${ }^{15}$ o que pode estar relacionado à mudança principal contida na Convenção Americana em relação a modelos notados em demais tribunais internacionais: a possibilidade de os Estados do sistema as solicitarem. ${ }^{16}$ Um número maior de opiniões consultivas permitiu à Corte delimitar sua jurisdição, ainda que muitas vezes de modo expansivo ${ }^{17}$ pela aplicação do princípio kompetenz kompetenz. A Corte se atribuiu amplos poderes jurisdicionais tanto na interpretação da Convenção quanto ao próprio funcionamento do Sistema Interamericano ${ }^{18}$ e os utilizou, por exemplo, para determinar quais documentos normativos poderiam ser objeto de sua interpretação no âmbito consultivo. ${ }^{19}$

15 Para uma comparação entre as competências consultivas dos sistemas regionais de proteção de direitos humanos e da CIJ, ver Asta, Gabriele, La funzione consultiva delle Corti Regionali dei Diritti Umani, Nápoles, Scientifica, 2019.

16 O artigo 64 da Convenção Americana estabelece duas possibilidades de solicitação de opiniões consultivas. A primeira, referente ao artigo 64.1, trata de uma interpretação a ser feita pela Corte Interamericana acerca da $\mathrm{CADH}$ ou de "outros tratados concernentes à proteção dos direitos humanos nos Estados americanos”, cujo pedido pode vir dos órgãos ou dos Estados membros da OEA. Já o artigo 64.2 permite que o Estado da OEA solicite avaliação da compatibilidade de uma disposição de seu direito interno com os referidos instrumentos. Por outro lado, uma opinião consultiva a ser requisitada à Corte Internacional de Justiça necessita angariar o apoio de um certo número de Estados para que determinado órgão realize o pedido. Sobre a dinâmica da CIJ, consultar: artigo 96 da Carta da ONU. Sobre a questão, ver OellersFrahm, Karin, “Article 96 UN Charter”, e, na mesma obra, Frowein, Jochen e Oellers-Frahm, Karin, “Article 65”, em Zimmermann, Andreas et al. (orgs.), The Statute of the International Court of Justice: A Commentary, Oxford, Oxford University Press, 2012.

17 Tal expansão ocorre toda vez em que a Corte altera, alarga ou abrange parâmetros textualmente ou jurisprudencialmente definidos em relação ao conteúdo de determinados direitos reconhecidos na Convenção Americana (competência ratione materiae), ou aos aspectos que envolvem sua adjudicação perante o Sistema (competência ratione personae e ratione loci, particularmente).

18 Nesse sentido, OC-21/14, para. 17, e Voto do Juiz A. A. Cançado Trindade, para. 5, na OC-15/97.

19 Ver, supra, 14. 
Assim, o exercício da função consultiva da Corte Interamericana foi limitado no âmbito de sua própria jurisprudência. A prática judicial interamericana demonstra que, sempre que um parecer é requerido, existem tentativas processuais de convencimento da Corte de não pronunciamento. Numa recente opinião, a Corte sistematizou os critérios que motivam sua recusa a tramitar e responder a uma solicitação de parecer consultivo, de maneira a indicar que um pedido:

a) não deve encobrir um caso contencioso ou pretender obter prematuramente um pronunciamento sobre um tema ou assunto que poderia eventualmente ser submetido à Corte por um caso contencioso; b) não deve utilizar-se como um mecanismo para obter um pronunciamento indireto de um assunto em litígio ou em controvérsia no nível interno; c) não deve ser utilizada como um instrumento de um debate político interno; d) não deve abarcar, de maneira exclusiva, temas sobre os quais a Corte já se pronunciou em sua jurisprudência; e) não deve buscar a resolução de questões fáticas, a não ser que busque averiguar o sentido, propósito e razão das normas internacionais sobre direitos humanos e, sobretudo, contribuir com os Estados membros e os órgãos da OEA para que cumpram de maneira cabal e efetiva suas obrigações internacionais. ${ }^{20}$

Alguns elementos interessantes emergem da lista indicada pela Corte. O primeiro deles é o fato de que a Corte, ao menos em teoria, realiza uma estrita divisão entre a função contenciosa e a consultiva: não pode a função consultiva servir para tergiversar o consentimento em relação a uma contro-

20 Corte IDH, La institución del asilo y su reconocimiento como derecho humano en el sistema interamericano de protección (interpretación y alcance de los artículos 5, 22.7 y 22.8, en relación con el artículo 1.1 de la Convención Americana sobre Derechos Humanos), Opinião Consultiva OC-25/18 de 30 de maio de 2018, Série A núm. 25, para. 46. No original: "a) no debe encubrir un caso contencioso o pretender obtener prematuramente un pronunciamiento sobre un tema o asunto que podría eventualmente ser sometido a la Corte a través de un caso contencioso; b) no debe utilizarse como un mecanismo para obtener un pronunciamiento indirecto de un asunto en litigio o en controversia a nivel interno; c) no debe utilizarse como un instrumento de un debate político interno; d) no debe abarcar, en forma exclusiva, temas sobre los que la Corte ya se ha pronunciado en su jurisprudencia, y e) no debe procurar la resolución de cuestiones de hecho, sino que busca desentrañar el sentido, propósito y razón de las normas internacionales sobre derechos humanos y, sobre todo, coadyuvar a los Estados miembros y a los órganos de la OEA para que cumplan de manera cabal y efectiva sus obligaciones internacionales". 
vérsia ou sobre fatos existentes (itens [a], [b] e [e]). ${ }^{21} \mathrm{O}$ segundo elemento é o fato de que a jurisdição consultiva $\mathrm{CtIDH}$ não deve ser instrumentalizada para resolver questões internas no interior dos Estados (itens [b] e [c]). O terceiro elemento que emerge é particularmente interessante. Ao limitar sua jurisdição consultiva, a Corte reafirma (item [e]) que a função desta é a elucidação de normas internacionais a fim de que Estados membros possam efetivar suas obrigações internacionais. Contudo, a Corte não limita a própria expansão ou alargamento das obrigações já existentes. Poder-se-ia sugerir que a Corte parece estar ciente da capacidade expansiva de sua jurisdição na medida em que não se autolimita em relação ao seu campo de atuação ao mesmo tempo que não reconhece unicamente a Convenção como sua fonte de interpretação, abrangendo também outras "normas internacionais sobre direitos humanos".

Não por acaso, a delimitação de forma ampla da competência consultiva pela Corte foi alvo de crítica por analistas, seja pela sua incerteza de aplicação ${ }^{22}$ ou pela sua própria tendência expansiva em comparação aos limites normativos. ${ }^{23}$ Outros, contudo, indicam o surgimento desses critérios limitadores supracitados como algo criticável para o papel da Corte no contexto interamericano, ${ }^{24}$ vez que a Corte os utiliza de maneira flexível. ${ }^{25}$

Isso se mostra mais problemático ao perceber que a produção consultiva não possui efeitos autocontidos, porque gera consequências na atividade

21 Sobre a questão, ver Lima, Lucas Carlos, “A opinião sobre o arquipélago de Chagos: a jurisdição consultiva da Corte Internacional de Justiça e a noção de controvérsia”, Revista da Faculdade de Direito da Universidade Federal de Minas Gerais, núm. 75, 2019, pp. 281-302.

22 Roa, Jorge Ernesto, La función consultiva de la Corte Interamericana de Derechos Humanos, Bogotá, Universidad Externado de Colombia-Instituto de Estudios Constitucionales, 2015; Candia Falcón, Gonzalo, "Causales de inadmisibilidad de opiniones consultivas: reforzando el carácter subsidiario del sistema interamericano de derechos humanos", Revista Chilena de Derecho, vol. 45, 2018, pp. 57-80; Benz, Eleanor, “The Inter-American Court's Advisory Function Continues to Boom - A Few Comments on the Requests Currently Pending”, EJIL: Talk!, 25 de novembro de 2019.

23 Schmid, Julie Calidonio, "Advisory Opinions on Human Rights: Moving Beyond a Pyrrhic Victory”, Duke Journal of Comparative \&International Law, vol. 16, 2006, pp. 415-456.

${ }^{24}$ Bailliet, Cecilia M., "The Strategic Prudence of the Inter-American Court of Human Rights: Rejection of Requests for an Advisory Opinion”, Revista de Direito Internacional, vol. 15, 2018, pp. 254-276.

25 Logo após elencar os critérios, a Corte afirma, na OC-25/18 (para. 46): "Sin embargo, los criterios desarrollados no son una lista exhaustiva, y tampoco constituyen límites infranqueables, en tanto corresponde a la Corte evaluar en cada solicitud concreta la pertinencia de ejercer su función consultiva”. 
Esta revista forma parte del acervo de la Biblioteca Jurídica Virtual del Instituto de Investigaciones Jurídicas de la UNAM

contenciosa da Corte. Pode-se destacar, dentre elas, a discussão das funções da Comissão (OC-15/97 e OC-19/05) e até de regras procedimentais, ${ }^{26}$ além do estabelecimento de interpretações acerca do conteúdo dos direitos materiais contidos na Convenção Americana. Ademais, existe amplo debate sobre a obrigatoriedade das opiniões consultivas. ${ }^{27}$ Fato é que, na prática, a interpretação de direitos em via consultiva é comumente seguida pela Corte nos casos contenciosos diante dela sublevados. Tal circunstância lança sombras à tentativa de hermética dissociação entre função consultiva e contenciosa sugerida pela Corte Interamericana.

Essa incerteza não colocava maiores problemas jurídicos em relação aos impactos, no âmbito contencioso, das opiniões que analisavam obrigações e critérios de aplicação de direitos materiais. Isso porque, em utilização

26 A OC-20/09 discutiu se o artigo 55 da CADH previa somente a possibilidade em litígios interestatais de juízes ad hoc e da participação dos juízes nacionais eleitos, ao contrário da prática do tribunal até então, que permitia que atuações em casos de petições individuais. Em decorrência disso, com a alteração do Regulamento da Corte em 2009, os artigos 19 e 20 foram modificados para comportar as observações. Assim, alterações no Regulamento motivadas por declarações ocorridas no âmbito consultivo poderiam apontar essa predisposição de se "alterar as regras do jogo".

27 A atribuição de força vinculante é incompatível com a Convenção Americana sobre Direitos Humanos, na medida em que o artigo 68.1 somente compromete os Estados com as decisões da Corte em que são parte, ou seja, sentenças obtidas no meio contencioso que condenam o Estado. Assim, a inexistência de previsão similar para os pareceres consultivos não garante a elas obrigatoriedade de cumprimento pelo solicitante e demais afetados. Isso não significa que o conteúdo de um parecer será completamente ignorado, afinal, a solicitação vinda de um ou mais Estados indica a vontade de obter maior esclarecimento sobre como implementar alguma obrigação contraída, ou acerca do funcionamento de demais disposições do Sistema. Por conseguinte, a função consultiva enfrenta comumente temas controversos e em evolução no direito internacional. Sobre a questão, em âmbito geral, ver Oellers-Frahm, Karin, "Lawmaking Through Advisory Opinions?”, German Law Journal, vol. 12, 2011, pp. 1033-1056. Em específico sobre a CtIDH, destaca-se a visão da não obrigatoriedade notada por ex-juízes, como Nikken, Pedro, "La función consultiva de la Corte Interamericana de Derechos Humanos", em Corte IDH, Memoria del Seminario "El sistema interamericano de protección de derechos humanos en el umbral del siglo XXI”, San José, Corte Interamericana de Direitos Humanos, 2003, t. I, p. 176, e Buergenthal, Thomas, "The Advisory Practice of the Inter-American Human Rights Court", American Journal of International Law, vol. 79, 1985, p. 18. Além disso, o grande impacto das opiniões na prática estatal pode ser exemplificado pela análise do ex-Presidente da CtIDH, em Cançado Trindade, Antônio Augusto, "The Humanization of Consular Law: The Impact of Advisory Opinion No. 16 (1999) of the Inter-American Court of Human Rights on International Case-Law and Practice”, Chinese Journal of International Law, vol. 6, 2007, pp. 1-16. 
do chamado método interpretativo evolutivo, ${ }^{28}$ as determinações da Corte traziam análises de compatibilidade de condutas e o estabelecimento de standards mais elevados para execução das obrigações associadas a esses direitos.

Dessa forma, em aplicação de técnicas de valorização da abertura normativa, ${ }^{29}$ o comportamento da Corte em relação à análise material nas OCs anteriormente era marcado por uma identificação da compatibilidade de certas condutas com a proteção de direitos estabelecida na CADH. Assim, na OC-3-83 a Corte conclui que a pena de morte é expressamente proibida à luz do direito à vida (artigo 4o.). ${ }^{30} \mathrm{Na} \mathrm{OC}-5 / 85$, a Corte determina que a coligação obrigatória de periodistas é incompatível com a liberdade de expressão (artigo 13). ${ }^{31}$ Nas OCs 8 e 9, de 1987, estriba-se a interpretação de que garantias judiciais e de devido processo são irrevogáveis em contextos de exceção. Todos esses exemplos demonstram que a Corte utiliza sua via consultiva para alargar o alcance dos enunciados normativos da Convenção

28 Ver, supra, 10.

29 Dentre as técnicas do método interpretativo evolutivo, tem-se uma categoria denominada "valorização da abertura normativa", explicada desde a OC-1/82. Nela determinou-se (paras. 33 e ss.) a utilização das normas gerais de interpretação codificadas nos artigos 31 e 32 da Convenção de Viena sobre o Direito dos Tratados, associado ao critério do artigo 29.b da CADH, que valoriza o princípio pro persona, o qual "consiste em prover uma interpretação que possa outorgar aos indivíduos uma proteção máxima, ou seja, pronta a privilegiar a interpretação mais favorável aos indivíduos”. Assim, o método predominantemente utilizado pela Corte é a interpretação de tratados com um viés teleológico, para alcançar esse fim de maior proteção, ainda que outros (textual, histórico e sistemático) sejam acessados em casos complexos. Burgorgue-Larsen, Laurence, "El contexto...”, op. cit., pp. 108 e 109. No mais, a própria Corte declarou a priorização do método teleológico e sistemático, em detrimento do enfoque no conceito comum dos termos contidos nos dispositivos, para aplicação da norma mais favorável. Quanto a isso, ver Corte IDH, Caso Ricardo Canese vs. Paraguai. Mérito, reparações e custas, Sentença de 31 de agosto de 2004, Série C núm. 111, para. 181; Corte IDH, Caso González y otras ("Campo Algodonero") vs. México. Exceções preliminares, matéria, reparações e custas, Sentença de 16 de novembro de 2009, Série C núm. 205, para. 59; Corte IDH, Caso Artavia Murillo y otros (fecundación in vitro) vs. Costa Rica. Exceções preliminares, mérito, reparações e custas, Sentença de 28 de novembro de 2012, para. 257.

30 Corte IDH, Restricciones a la pena de muerte (arts. 4.2 y 4.4 Convención Americana sobre Derechos Humanos), Opinião Consultiva OC-3/83 de 8 de setembro de 1983, Série A núm. 3, ponto 1 do dispositivo, para. 76.

31 Corte IDH, La colegiación obligatoria de periodistas (arts. 13 y 29 Convención Americana sobre Derechos Humanos), Opinião Consultiva OC-5/85 de 13 de novembro de 1985, Série A núm. 5, dispositivo, para. 85 . 
a específicas situações de fato. O resultado de tal exercício é uma expansão material do conteúdo da Convenção. ${ }^{32}$

As opiniões da década de 2000 também se utilizam do método de interpretação expansiva, principalmente pela técnica de utilização dos conceitos de não discriminação (texto convencional) e vulnerabilidade (desenvolvido jurisprudencialmente). A Corte Interamericana aproveita a presença na Convenção do princípio da não-discriminação (artigo 1.1) para pôr fim às situações estruturais em que os indivíduos e/ ou grupos tenham sofrido uma conduta discriminatória, a partir de uma perspectiva histórica, sociológica, econômica ou política. Assim, resultou-se a construção, no contencioso, de um direito indígena e da luta contra estereótipos de indivíduos LGBTQIA + ${ }^{33}$ posteriormente reforçados, respectivamente, pela OC-22/16 e pela OC24/17. Nesses casos, as opiniões consultivas são utilizadas para consolidação de interpretações anteriormente desenvolvidas.

Outra atenção se deu, já no âmbito consultivo, aos direitos dos trabalhadores migrantes, na OC-18/03, e das crianças, nas OC-17/02 e 21/14, para que se beneficiem de uma proteção jurídica elementar. ${ }^{34}$ Dessa forma, ao reconhecer grupos como vulneráveis, supõe-se a adoção de medidas especiais para garantir suas proteções, ${ }^{35}$ de modo que o conteúdo dessas decisões contém verdadeiras delimitações de obrigações específicas, ao que chamaram políticas públicas. ${ }^{36}$

Ademais, como exemplos de decisões impactadas pelos pareceres, um dos primeiros casos analisados pela CtIDH, Velásquez Rodríguez vs. Honduras, em que o país foi condenado pela violação à liberdade e integridade pessoal da vítima, cuja fundamentação se valeu da OC-6/86, que estabeleceu o dever de respeito e garantia das obrigações dos Estados em relação aos direitos da CADH. ${ }^{37}$ Outro exemplo pode ser verificar no julgado Manuel Cepeda Vargas vs. Colômbia, em que a Corte recorreu, também dentre outras, à OC-3/83,

32 Observa-se que a OC-7/86 não define um direito material, mas esclarece como interpretar e aplicar o direito de retificação ou resposta, contido no artigo 14 da CADH, à luz dos artigos 1.1 e 2o. (p. 8).

33 Burgorgue-Larsen, Laurence, "El contexto...”, op. cit., p. 129.

34 Idem.

35 Ibidem, p. 130.

36 Candia Falcón, Gonzalo, op. cit., p. 72.

37 Corte IDH, Caso Velásquez Rodríguez vs. Honduras. Mérito, Sentença de 29 de julho de 1988, Série C núm. 4, para. 165 e pontos 2 e 3 do dispositivo, para. 194. 
para avaliar a proporcionalidade das medidas estatais com o fim de sancionar agentes públicos que cometeram delitos contra membros da oposição. ${ }^{38}$

Em suma, é possível apontar que a Corte expande direitos e os efeitos de suas violações via pareceres consultivos que, no mínimo, não estavam claros nas fontes normativas que interpreta. Um problema emerge no âmbito de duas opiniões mais recentes. Na ocasião, a expansão de jurisdição não se ateve ao âmbito consultivo, vez que a Corte se pronunciou sobre regras que alteram os limites de sua competência contenciosa. Assim, aumenta-se as possibilidades de novos casos serem submetidos para análise jurisdicional da Corte, e os efeitos desse fenômeno já podem ser percebidos em julgamentos recém decididos.

\section{A EXPANSÃO DA JURISDIÇÃO CONTENCIOSA ATRAVÉS} DA JURISDIÇÃO CONSULTIVA: PROBLEMAS RECENTES

Que as interpretações sobre o corpus juris internacional dos direitos humanos desenvolvidas pela Corte Interamericana no âmbito consultivo são adotadas no âmbito contencioso não parece ser particularmente surpreendente, sobretudo à luz da prática contenciosa de outras cortes internacionais. ${ }^{39}$ É uma questão de consistência jurisprudencial que a solicitação de interpretação sobre um dispositivo da Convenção seja posteriormente congruentemente aplicado pelo órgão jurisdicional diante de casos concretos. Todavia, em duas opiniões consultivas recentes, técnicas interpretativas expansivas foram utilizadas no âmbito consultivo com implicações diretas na delimitação do escopo jurisdicional contencioso da Corte. Em outras palavras, a Corte Interamericana de Direitos Humanos expandiu sua jurisdição contenciosa através da resposta a uma opinião consultiva requerida por um Estado.

Uma primeira expansão diz respeito à competência ratione personae, vez que a Corte firmou, na OC-22/16, versando sobre a titularidade de direitos de pessoas jurídicas no Sistema Interamericano, a possibilidade de peticionamento ao sistema por entes que originalmente não possuíam capacidade postulatória perante o sistema. É o caso de sindicatos, federações e

38 Corte IDH, Caso Manuel Cepeda Vargas vs. Colômbia. Exceções preliminares, mérito, reparações e custas, Sentença de 26 de maio de 2010, Série C núm. 213, para. 150.

39 Oellers-Frahm, Karin, “Lawmaking...”, op. cit., p. 1051. 
Esta revista forma parte del acervo de la Biblioteca Jurídica Virtual del Instituto de Investigaciones Jurídicas de la UNAM

confederações, pessoas jurídicas que foram reconhecidas como detentoras dos direitos de associação e liberdade de funcionamento, previstos no artigo 8.1.a do Protocolo de San Salvador. Esses direitos de proteção já haviam sido abordados em casos anteriores,${ }^{40}$ mas pela primeira vez a CtIDH "concluiu a titularidade dos direitos estabelecidos no artigo 8.1 do Protocolo dos sindicatos, das federações e das confederações, o qual lhes permite apresentar-se perante o sistema americano em defesa de seus próprios direitos". ${ }^{41}$ Esse é um desenvolvimento interessante, vez que, ao realizar tal reconhecimento, a CtIDH alarga o rol de entes peticionários e, por consequência, o número de clientes de sua jurisdição.

A Corte lançou mão de diversos argumentos para chegar a esta conclusão. Aduziu ter empregado as técnicas de interpretação de tratados da Convenção de Viena (artigos 31 e 32), ${ }^{42}$ a fim de realizar essa conclusão em 5 aspectos [(1) a (5)]. (1) Quanto à terminologia, deduziu que a escrita do artigo 8.1.a enseja a conclusão de que sindicatos, federações e confederações constituem pessoas jurídicas distintas de seus associados, com capacidades diferentes para contrair obrigações e adquirir e exercer direitos. ${ }^{43}$ (2) Isso estaria alinhado aos objetivos do Protocolo de San Salvador, que desde o preâmbulo anuncia a essencialidade desses direitos para salvaguardar a dignidade humana, a democracia e o direito dos povos do continente, de modo que a proteção desses direitos aos entes garante, inclusive, melhor gozo dos direitos dos trabalhadores. ${ }^{44}$

(3) Além disso, em uma interpretação sistêmica, destacou que a Carta da OEA, essencial para o Sistema, consagra no artigo 45.c a proteção da li-

40 A Corte havia anteriormente estabelecido que a liberdade de associação de entidades sindicais integra o corpus juris dos direitos humanos no caso Baena Ricardo y otros vs. Panamá (para. 158) e que os Estados eram obrigados, com base no artigo 8.1.a do Protocolo, a permitir que essas entidades operem livremente, no caso Huilca Tecse vs. Peru (para. 74).

41 Corte IDH, Titularidad de derechos de las personas jurídicas en el sistema interamericano de derechos humanos (interpretación y alcance del artículo 1.2, en relación con los artículos 1.1, 8, 11.2, 13, 16, 21, 24, 25, 29, 30, 44, 46 y 62.3 de la Convención Americana sobre Derechos Humanos, así como del artículo 8.1 A y B del Protocolo de San Salvador), Opinião Consultiva OC-22/16 de 26 de fevereiro de 2016, Série A núm. 22, para. 105. No original: “... ha concluido la titularidad de los derechos establecidos en el artículo 8.1. a del Protocolo de los sindicatos, las federaciones y las confederaciones, lo cual les permite presentarse ante el sistema interamericano en defensa de sus propios derechos".

42 Ibidem, para. 36.

43 Ibidem, paras. 91 e 92.

44 Ibidem, para. 98. 
berdade e independência das associações de trabalhadores e, no artigo 45.g, reconhece a contribuição dos sindicatos à sociedade. ${ }^{45}$ Essa interpretação se alinharia até mesmo ao princípio pro persona, pois não exclui ou limita o efeito que podem ter outros instrumentos. ${ }^{46}$ (4) Outro argumento usado pela Corte nessa opinião seria de que essa interpretação concede ao artigo 8.1.a o fim de "maior efeito útil", de maneira a reforçar a importância dos direitos civis e políticos e dos direitos econômicos sociais e culturais. ${ }^{47}$ (5) Por último, de forma complementar, a CtIDH ainda examinou os trabalhos preparatórios, cuja discussão do artigo 19.6, o qual determina os direitos que a Corte pode reconhecer contenciosamente, sugeriria que a intenção dos Estados sempre foi de garantir os direitos das organizações sindicais como direitos de exigibilidade imediata. ${ }^{48}$

O uso dessas técnicas interpretativas pela Corte não é particularmente inovador. A singularidade do exercício é a sua conclusão expansiva de peticionários $^{49}$ - inferência que parece contrastar com o texto da Convenção Americana - Em outras palavras, a Corte não empregou nenhuma técnica interpretativa diferente das que já empregara no passado para realizar a expansão de sua jurisdição a novos peticionários.

Um segundo exemplo, talvez ainda mais cristalino, em que a CtIDH expandiu sua jurisdição ocorreu na OC-23/17 sobre O Meio Ambiente e Direitos Humanos. A relação entre meio ambiente e direitos humanos tem sido um tópico de recente atenção por parte de órgãos internacionais, cortes e doutrina, e a questão também se verifica no âmbito interamericano. ${ }^{50}$

45 Ibidem, para. 94.

46 Ibidem, para. 95.

47 Ibidem, para. 98.

48 Ibidem, para. 100.

49 A própria Corte Interamericana conclui, na OC-22/16, que o critério contido no artigo 1.2 da CADH não atribui a pessoas jurídicas a titularidade de direitos (para. 71). Contudo, essa expansão para pessoas jurídicas é realizada na Opinião não só em reconhecimento ao que prevê o Protocolo de San Salvador para entidades trabalhistas, mas também, quanto à Convenção Americana, em reconhecimento do que já era aplicado no contencioso, de titulação de direitos referentes a comunidades indígenas. Ela cria essa exceção ao se apoiar em demais instrumentos jurídicos do sistema, internacionais e legislações internas, os quais concedem aos povos direitos, além de afirmar que certos direitos são socialmente experienciados pelos povos indígenas de maneira coletiva, como o direito à propriedade (para. 83).

50 Pode-se citar, por exemplo: Boyle, Alan, "Human Rights and the Environment", em Boer, Ben, Environmental Law Dimensions of Human Rights, Oxford, Oxford University Press, 2015, pp. 
Esta revista forma parte del acervo de la Biblioteca Jurídica Virtual del Instituto de Investigaciones Jurídicas de la UNAM

Recorda-se que o litigar de questões ambientais autonomamente perante jurisdições de direitos humanos é um aspecto bastante limitado destas cortes internacionais. ${ }^{51}$ No momento do design institucional da Corte, o número de direitos a ser individualmente litigados envolviam, em essência, direitos civis e políticos. Não por acaso os direitos econômicos sociais e culturais foram relegados a um segundo documento, o Pacto de San Salvador. A Corte Interamericana, contudo, aproveitou a ocasião do pedido de parecer consultivo requerido por parte da Colômbia para concluir que direitos ambientais poderiam ser adjudicados diretamente em relação à Convenção — algo que não se encontra previsto no texto do tratado-.${ }^{52} \mathrm{Na}$ ocasião da opinião 23, a Corte parece ter sido inovadora e, por consequência, expandido sua jurisdição em relação a pelo menos três aspectos: (a) inseriu o meio ambiente como direito autônomo sob o artigo 26 da CADH; (b) alargou a noção de jurisdição para fins de responsabilização internacional; (c) incorporou à obrigação de respeito ao meio ambiente sadio standards protetivos em relação ao meio ambiente bastante avançados.

(a) A Corte considerou o direito ao meio ambiente sadio como integrante ${ }^{53}$ do artigo 26 da Convenção, ${ }^{54}$ primeiramente em referência à Carta da OEA, pois o dispositivo da CADH protegeria os direitos nela contidos de-

201-239; Pavoni, Riccardo, "Environmental Jurisprudence of the European and Inter-American Courts of Human Rights", em Boer, Ben, Environmental Law Dimensions of Human Rights, Oxford, Oxford University Press, 2015, pp. 69-106.

51 Sobre a questão, ver Shelton, Dinah, "Human Rights and the Environment: Substantive Rights”, em Fitzmaurice, Malgosia et al. (eds.), Research Handbook on International Environmental Law, Cheltenham, Edward Elgar Publishing, 2010; e, de maneira geral, Pavoni, Riccardo, Interesse pubblico e diritti individuali nella giruisprudenza ambientale della Corte Europea dei Diritti Umani, Nápoles, Scientifica, 2013.

52 O artigo 11 do Protocolo de San Salvador prevê o "direito a um meio ambiente sadio". Todavia, o artigo 19.6 no Protocolo firma que somente os direitos estabelecidos nos dispositivos 8.1.a (liberdade sindical) e 13 (educação), caso violados por um Estado parte do documento, podem ser judicializáveis perante o sistema de peticionamento que envolve a Comissão e a Corte.

53 Vale destacar que Burgorgue-Larsen ("El contexto...”, op. cit., p. 124) aponta a integração como associada à "técnica de identificação de novos direitos", enquanto parte da metodologia de interpretação evolutiva. Nela, identifica-se um direito não presente nos termos do artigo a que se quer atribuí-lo.

54 Corte IDH, Medio ambiente y derechos humanos (obligaciones estatales en relación con el medio ambiente en el marco de la protección y garantía de los derechos a la vida y a la integridad personal interpretación y alcance de los artículos 4.1 y 5.1, en relación con los artículos 1.1 y 2 de la Convención 
rivados das normas econômicas, sociais e sobre educação, ciência, e cultura. ${ }^{55}$ A Corte utiliza-se da regra de interpretação do artigo 29 da Convenção Americana para atribuir ao artigo 26 os direitos da Carta da OEA, da Declaração Americana e de outros tratados internacionais da mesma natureza, replicando a fundamentação criada desde o caso Lagos del Campo vs. Peru, de 2017. Na ocasião, a Corte expandiu pela primeira vez o escopo do artigo 26, permitindo litigar direitos trabalhistas e de liberdade de associação abarcados pelo dispositivo a título de desenvolvimento progressivo. ${ }^{56}$

Americana sobre Derechos Humanos), Opinião Consultiva OC-23/17 de 15 de novembro de 2017, Série A núm. 23, para. 57.

55 Artigos 30, 31, 33 e 34 da Carta da Organização dos Estados Americanos.

56 Corte IDH, Caso Lagos del Campo vs. Peru. Exceções preliminares, mérito, reparações e custas, Sentença de 31 de agosto de 2017, Série C núm. 340, para. 142. A Corte estabeleceu que o artigo 26 da CADH estava sujeito às obrigações gerais contidas nos artigos 1.1 e 2o., que dizem respeito à obrigatoriedade de respeitar os direitos e ao dever de adotar disposições de direito interno para concretizá-los, assim como estão os artigos 3o. a 25, passíveis de litigância, além de que o 26 protege os direitos derivados dos demais tratados. Segundo a Corte, estes seriam derivados das normas econômicas, sociais e sobre educação, ciência e cultura contidas na Carta da OEA. Assim, a CtIDH reconheceu na sentença o direito à estabilidade laboral como protegido por esses dispositivos e o declarou o artigo 26 violado pelo Estado peruano. No ano seguinte, a Corte reinterpretou a possibilidade de judicialização dos DESCA, em aplicação da Convenção de Viena sobre o Direito dos Tratados, no caso Cuscul Pivaral y otros vs. Guatema1a. À ocasião, entendeu que é a interpretação literal do artigo 26 que permite trazer outros instrumentos, pois "es posible afirmar que se refiere precisamente al deber de los Estados de lograr la efectividad de los «derechos» que sea posible derivar de la Carta de la OEA” (para. 78). Igualmente, afirmou, pela intepretação sistêmica do contexto da própria Convenção Americana, que "al existir una obligación de los Estados de respetar y garantizar los derechos contemplados por el artículo 26, en los términos del artículo 1.1 de la Convención, la Corte tiene competencia para calificar si existió una violación a un derecho derivado del artículo 26 en los términos previstos por los artículos 62 y 63 de la Convención” (para. 84). Ademais, também pela interpretação sistêmica, ela busca contornar a limitação de litigância do artigo 19.6 do Protocolo de San Salvador ao afirmar que "no queda duda que la voluntad de los Estados sobre la competencia de la Corte para pronunciarse sobre violaciones al Protocolo de San Salvador encuentra sus límites en los derechos sindicales y el derecho a la educación”, mas "no debe ser interpretado como un precepto que limite el alcance de los derechos protegidos por la Convención, ni sobre la posibilidad de la Corte para conocer sobre violaciones a estos derechos. Por el contrario, el Tribunal advierte que una interpretación sistemática y de buena fe de ambos tratados lleva a la conclusión de que, al no existir una restricción expresa en el Protocolo de San Salvador, que limite la competencia de la Corte para conocer sobre violaciones a la Convención, esta limitación no debe ser asumida por este Tribunal" (paras. 87 e 88). Ao fim, após reafirmar a intepretação teleológica, recorre ao método complementar de 
Ulterior argumento utilizado pela Corte para justificar a autonomia de direitos ambientais sob o artigo 26 foi o reiterar da interdependência e indivisibilidade existente entre os direitos civis e políticos com os econômicos, sociais e culturais. ${ }^{57} \mathrm{~A}$ interpretação expansiva da Corte inserindo o direito autônomo ao meio ambiente sadio sob a rubrica do artigo 26 é inovadora. Não por acaso, no âmbito da própria Corte, a tese gerou resistências. Em seu voto dissidente à opinião, o juiz Vio Grossi aguilhoou a decisão da Corte sob o argumento de que "os direitos sob análise não se encontram compreendidos ou contidos na Convenção e, por isso, não podem ser objeto do sistema de proteção que ela [a Corte] contempla”. ${ }^{58}$ Vio Grossi parecia antever a possibilidade de, uma vez declarada a autonomia esses direitos, tê-los como objeto do contencioso individual.

(b) A segunda questão em que a Corte parece ter inovado na opinião 23 refere-se ao alcance de sua jurisdição. Isto porque pronunciou-se sobre novo critério de aplicação extraterritorial dos direitos associados ao meio ambiente. Segundo a Corte "uma pessoa está submetida à jurisdição de um Estado, no que diz respeito a uma conduta cometida fora do território desse Estado (condutas extraterritoriais) ou com efeitos fora desse território", em situações em que "referido Estado está exercendo autoridade sobre a pessoa ou quando se encontre sob seu controle efetivo, seja dentro ou fora de seu território". ${ }^{59}$ Ainda que tenha salientado que esse controle extraterritorial é excepcional, existe um claro entendimento que as obrigações incumbentes a um Estado parecem ter se expandido no novo entendimento da Corte a qualquer atividade de entes sob seu controle fora do território.

A novidade se encontra no expresso reconhecimento do critério de controle efetivo, cuja definição no âmbito da jurisprudência da CtIDH é incer-

recorrer aos trabalhos preparatórios da Convenção Americana para fazer menção ao desejo, à época de estabelecer com o artigo 26 "una disposición que establezca cierta obligatoriedad jurídica... en su cumplimiento y aplicación” (para. 95). Corte IDH, Caso Cuscul Pivaral y otros vs. Guatemala. Exceções preliminares, mérito, reparações e custas, Sentença de 23 de agosto de 2018, Série C núm. 359, paras. 75 e ss. Isso aponta para uma tentativa de reforço constante ao fundamento sobre a judicialização dos DESCA.

57 Corte IDH, OC-23/17, para. 57.

58 Corte IDH, OC-23/17, Voto concorrente do juiz Eduardo Vio Grossi, para. 5. No original: "los derechos en comento no se encuentran comprendidos o contenidos en la Convención y, por ende, no pueden ser objeto del sistema de protección que ella contempla”.

59 Corte IDH, OC-23/17, para. 81. 
Esta revista forma parte del acervo de la Biblioteca Jurídica Virtual del Instituto de Investigaciones Jurídicas de la UNAM

ta. ${ }^{60} \mathrm{~A}$ expansão da competência ligada a esse novo critério é dupla. Surge uma nova possibilidade de a Corte julgar um caso cuja suposta violação de um direito ocorre em um "local" diferente do tradicionalmente abarcado por sua jurisdição. Ademais, essa violação extraterritorial poderia atingir pessoas que anteriormente não seriam consideradas vítimas peticionantes perante o sistema, por estarem sob jurisdição de um Estado que não reconheceu a competência da Corte. Tal parecer encontrou alguma perplexidade por parte dos comentadores. ${ }^{61}$

(c) A Corte parece ter sido particularmente inovadora também quando incorporou e reconheceu a existência de certas obrigações para os Estados cujo reconhecimento no campo do direito internacional público é ainda aberto à discussão. Um exemplo nesse sentido é o expresso reconhecimento da obrigatoriedade do princípio da precaução no direito internacional. ${ }^{62}$ Alguns Estados preferem a defesa de uma "abordagem precaucional", como apontado pela jurisprudência de outros tribunais internacionais. ${ }^{63}$ Nessa passagem, a CtIDH dá a impressão de ter incorporado ao seu corpus juris obrigações ainda em formação no âmbito da comunidade dos Estados.

As três expansões acima indicadas possuem impacto no futuro contencioso da Corte Interamericana vez que robusteceu os direitos litigáveis contenciosamente sob o artigo 26 (incluindo claramente o direito ao meio ambien-

60 A Comissão Interamericana de Direitos Humanos, a partir da atuação de sua Relatoria Especial sobre Direitos Econômicos, Sociais, Culturais e Ambientais (REDESCA) tentou apontar caminhos para a aplicação do critério do controle efetivo. Sugeriu-se que sejam avaliados níveis de controle, desde a possibilidade de uma empresa cometedora de alguma violação a direitos ambientais ser efetivamente estatal ou exercedora de alguma atividade delegada, até níveis menores, como pela averiguação de o Estado ter efetivamente exercido seu dever de fiscalização e exigência do cumprimento de normas ambientais por ela. CIDH, Informe sobre empresas y derechos humanos: estándares interamericanos, OEA/Ser.L/V/II, CIDH/REDESCA/ INF.1/19, 1o. de novembro de 2019, paras. 152 e ss., disponível em: http://www.oas.org/es/ cidh/informes/pdfs/EmpresasDDHH.pdf.

61 Sobre a questão, ver Papantoniou, Angeliki, “Advisory Opinion on the Environment and Human Rights”, American Journal of International Law, vol. 112, 2018, pp. 460-466; Estupiñan Silva, Rosmerlin, "Primera opinión interamericana sobre medio ambiente: ¿derecho exigible o decisión ultra vires?”, Criterio Jurídico Garantista, vol. 11, pp. 61-80.

62 Corte IDH, OC-23/17, paras. 175 e ss., e tópico 6 do dispositivo, para. 244.

63 Kelly, Elsa, "The Precautionary Approach in the Advisory Opinion Concerning the Responsibilities and Obligations of States Sponsoring Persons and Entities with Respect to Activities in the Area", em International Tribunal for the Law of the Sea, The Contribution of the International Tribunal for the Law of the Sea to the Rule of Law: 1996-2016, Leiden, Brill, 2017. 
te sadio e outros), ${ }^{64}$ alargou a noção de jurisdição extraterritorial e, ainda, incorporou standards internacionais mais avançados na correta interpretação desses direitos. Esses recentes passos parecem contrastar com uma atividade mais contida da Corte, inclusive, ao se comparar com o desenvolvimento anterior no seio da competência consultiva relativo aos direitos econômicos, sociais e culturais e ambientais (DESCA). ${ }^{65}$ Por exemplo, na OC-18/03, optou-se pela via da não-discriminação para declarar que todos os migrantes trabalhadores gozam de igualdade perante a lei, sem importância de seu status migratório, de modo a desenvolver com cautela direitos trabalhistas, adotando-se de um fundamento jurídico menos controverso, ${ }^{66}$ posição essa não mais adotada.

Quanto aos efeitos desses pareceres já constatados no contencioso, podese apontar que as conclusões da OCs 22 ainda não repercutiram no contencioso da Corte. Todavia, recente decisão da Corte Interamericana aplicou o reconhecimento dos direitos ao meio ambiente saudável, à água, à alimentação e à participação e atividade cultural como incluído no artigo 26.

Na sentença de 6 de fevereiro de 2020, no caso Comunidades Indígenas Miembros de la Asociación Lhaka Honhat (Nuestra Tierra) vs. Argentina, a Corte Interamericana encontrou ocasião para aplicar os raciocínios desenvolvidos no âmbito da OC-23. Em síntese apurada, o caso cuida de 132 comunidades indígenas que tiveram seus direitos à terra diversas vezes desrespeitados aos longos dos anos e, em seu território, atividades de criollos causaram danos ambientais e redução da biodiversidade, o que foi comprovado por peritos. ${ }^{67}$ Por tais razões, a Corte, inter alia, condenou a Argentina pela violação do

64 Corte IDH, OC-23/17, para. 66: "The Court considers that the rights that are particularly vulnerable to environmental impact include the rights to life, personal integrity, private life, health, water, food, housing, participation in cultural life, property, and the right to not be forcibly displaced".

65 Sobre a questão, ver Ruiz-Chiriboga, Oswaldo R., "The American Convention and the Protocol of San Salvador: Two Intertwined Treaties: Non-Enforceability of Economic, Social and Cultural Rights in the Inter-American System”, Netherlands Quarterly of Human Rights, vol. 31, 2013, pp. 160-186.

66 Lyon, Beth, "The Inter-American Court of Human Rights Defines Unauthorized Migrant Worker's Rights for the Hemisphere: A Comment on Advisory Opinion 18”, New York University Review of Law and Social Change, vol. 28, 2004, pp. 547-565.

67 Corte IDH, Caso Comunidades Indígenas Miembros de la Asociación Lhaka Honhat (Nuestra Tierra) vs. Argentina. Mérito, reparações e custas, Sentença de 6 de fevereiro de 2020, Série C núm. 400, paras. 272-289. Sobre a questão de peritos em controvérsias ambientais, ver Lima, Lucas 
direito a um meio ambiente sadio, à alimentação adequada, à água, e à participação da vida cultural e identidade cultural. Vez que tais direitos não estão expressamente previstos na Convenção Americana, a Corte inclui-os sob a rubrica de desenvolvimento progressivo do artigo 26. Se, num primeiro momento, a estratégia da Corte foi confiar em sua jurisprudência anterior de incluir os DESC no rol de direitos litigáveis, a Corte ancorou-se no raciocínio desenvolvido na OC-23 para "se pronunciar sobre os direitos a um meio ambiente sadio, à alimentação adequada, à água e a participar da vida cultural a partir do artigo 26 da Convenção" ${ }^{68}$ Por fim, condenou o Estado pela violação do artigo 26 e atribuiu reparações a cada um dos direitos autonomamente.

Contudo, tal decisão relativa à judicialização dos DESCA no âmbito do artigo 26 ocorreu no cenário de uma Corte dividida. A divisão dos juízes no caso, que foi solucionada pelo infrequente voto de minerva da Presidente da Corte ${ }^{69}$ revela parte das tensões presentes na câmara de deliberação. Para os que estavam com a maioria, a ratio do princípio pro persona justificava

Carlos, "O uso de experts em controvérsias ambientais perante a Corte Internacional de Justiça”, Revista de Direito Internacional, vol. 13, 2016, pp. 245-261.

68 Corte IDH, Caso Comunidades Indígenas Miembros de la Asociación Lhaka Honhat (Nuestra Tierra) vs. Argentina..., cit., paras. 201 e ss. Do original: "La Corte advierte que este es el primer caso contencioso en el que debe pronunciarse sobre los derechos a un medio ambiente sano, a la alimentación adecuada, al agua y a participar en la vida cultural a partir del artículo 26 de la Convención".

69 É bastante incomum haver tamanha discordância na Corte. Em pesquisa realizada, foram levantados seis casos em que, por alguma composição, ocorreu a dissidência de três magistrados, sendo que a maior parte deles (caso Gangaram Panday vs. Suriname, caso Comunidad Indígena Yakye Axa vs. Paraguai e caso Wong HoWing vs. Peru) foi relativo à insuficiência probatória para condenar o Estado às alegações específicas mencionadas (dissidências ocorridas somente em relação a algum direito supostamente violado, com condenações ocorridas em demais), em um deles a discussão se centrou no montante indenizatório fixado (caso Salvador Chiriboga vs. Equador) e em um a questão levantava uma ponderação entre direitos (caso Mémoli vs. Argentina, em que se analisou a ponderação entre o direito à honra e à liberdade de expressão ocorrida no caso). Em apenas um deles a cisão dizia respeito à impossibilidade de declarar algum direito violado (caso Atala Riffo y niñas vs. Chile). Isso destaca a relevância da divisão da Corte notada no caso em análise, que não ocorreu nos demais casos de violação de DESCA pelo artigo 26, apesar da constante dissidência dos juízes Vio Grossi e Sierra Porto, pois o juiz uruguaio Pérez Manrique, cuja judicatura se iniciou em 2019, apenas emitiu votos separados concordantes nos casos anteriores sobre DESCA dos quais participou, caso Asociación Nacional de Cesantes y Jubilados de la Superintendencia Nacional de Administración Tributaria (ANCEJUB-SUNAT) vs. Peru e caso Hernández vs. Argentina. 
a expansão e judicialização dos DESCA. O juiz Mac-Gregor Poisot parece também ter levado em consideração o fato de que o Estado argentino não contestou a competência da Corte para adjudicar individualmente direitos ambientais (e outros) sob a rubrica do artigo $26 .{ }^{70}$ Não reconhecer a autonomia dos DESCA sob o artigo 26 implicaria, segundo ele, num retrocesso contrário à jurisprudência. Lógica similar parece se depreender do voto concorrente do juiz Pazmiño Freire, para quem, em certas circunstâncias, "se impõe implementar uma hermenêutica mais expansiva da norma para garantir uma melhor proteção do ser humano". ${ }^{71}$

$\mathrm{Na}$ voz dos três dissidentes alguns elementos e argumentos interessantes emergem. O juiz Manrique, por exemplo, claramente encampa a narrativa de uma Corte dividida em relação aos DESCA, cuja judicialização inicia-se em 2017. Tal divisão parece reforçar a ciência da Corte que seu exercício é o de inovação jurisprudencial. Dentre os juízes dissidentes que não concordaram com a violação autônoma do artigo 26, o juiz Manrique é aquele que oferece uma posição intermediária, sugerindo a violação dos DESCA juntamente a outros direitos reconhecidos na Convenção. Para ele "a Corte tem o dever convencional de fazer justiça nos casos concretos dentro dos limites previstos pelo direito dos tratados". ${ }^{72}$ Sua sugestão parece assemelhar-se à posição da Corte Europeia na matéria. ${ }^{73}$

As opiniões dissidentes mais contundentes parecem revelar algumas fragilidades da lógica expansiva da Corte. O juizVio Grossi opta pela argumentação da tradicional interpretação normativa nos termos da Convenção de

70 Corte IDH, Caso Comunidades Indígenas Miembros de la Asociación Lhaka Honhat (Nuestra Tierra) vs. Argentina, Voto concorrente do juiz Eduardo Ferrer Mac-Gregor Poisot, para. 6.

71 Corte IDH, Caso Comunidades Indígenas Miembros de la Asociación Lhaka Honhat (Nuestra Tierra) vs. Argentina, Voto concorrente do juiz Patricio Pazmiño Freire, para. 11. Do original: "bajo ciertas circunstancias, y a partir de este trasfondo es que, en ciertas oportunidades, se impone implementar una hermenéutica más expansiva de la norma en pos de garantizar una mejor protección del ser humano”.

72 Corte IDH, Caso Comunidades Indígenas Miembros de la Asociación Lhaka Honhat (Nuestra Tierra) vs. Argentina, Voto parcialmente dissidente do juiz Ricardo C. Pérez Manrique, para. 16. Do original: "la Corte tiene el deber convencional de hacer justicia en casos concretos dentro de los límites previstos por el derecho de los tratados".

73 A título de exemplo, o direito a um meio ambiente sadio é reconhecido em conexão com o direito à vida nos casos Fadeyeva vs. Rússia e Öneryildiz vs. Turquia, ou com o direito à vida privada e familiar, nos casos López Ostra vs. Espanha e Tatar vs. Suiça. Mais casos, conferir Corte Europeia de Direitos Humanos, "Factsheet - Environment and the ECHR", março de 2020. 
Viena sobre Direito dos Tratados. Em exegese pormenorizada analisando o texto do artigo 26 bem como outros documentos do corpus juris interamericano, Vio Grossi reprisa seu argumento aduzido na OC-23 de que as técnicas tradicionais de interpretação de tratado não permitem incluir DESCA como judicializáveis. Para Vio Grossi, a interpretação empregada pela Corte privilegia o método teleológico em detrimento de outros métodos haja vista a indicação textual. O juiz chileno parece sugerir que a interpretação da Corte é até mesmo contra legem na medida que negligencia o texto, permitindo a justiciabilidade destes direitos, quando sugere que a Corte não emprega "adequadamente os meios de interpretação previstos na Convenção de Viena, [conduzindo] a um resultado contrário à lógica e jamais desejado nem previsto na Convenção". ${ }^{74}$

O juiz Sierra Porto oferece uma opinião contundente na matéria: a de que a CtIDH não tem competência para adjudicar DESCA. ${ }^{75}$ Para o juiz colombiano, a Corte não possui competência expressa "nem pela Convenção Americana, nem pelo artigo 19.6 do Protocolo... interpretados à luz dos artigos 30 e 31 da Convenção de Viena sobre o Direito dos Tratados". ${ }^{76}$ Sierra Porto arvora seu posicionamento no fato de que os Estados membros do Protocolo de San Salvador só permitiram litigar alguns direitos, não estando meio ambiente (inter alia) entre eles. Conclui ainda que é problemático a referência a instrumentos internacionais de soft law por conveniência. ${ }^{77}$

A crítica presente nas opiniões dos três juízes é lancinante e revela a fratura no interior da Corte que expande sua competência para adjudicar DES-

74 Corte IDH, Caso Comunidades Indígenas Miembros de la Asociación Lhaka Honhat (Nuestra Tierra) vs. Argentina, Voto parcialmente dissidente do juiz Eduardo Vio Grossi, para. 88. Do original: "no emplear adecuadamente los medios de interpretación previstos en la Convención de Viena, conduce a un resultado contrario a la lógica y jamás deseado ni previsto en la Convención".

75 Corte IDH, Caso Comunidades Indígenas Miembros de la Asociación Lhaka Honhat (Nuestra Tierra) vs. Argentina, Voto parcialmente dissidente do juiz Humberto Antonio Sierra Porto, para. 6. Do original: "Reitero que el Tribunal no tiene esta competencia de manera expresa, ni por la Convención Americana, ni por el artículo 19.6 del Protocolo Adicional a la Convención Americana sobre Derechos Humanos en materia de Derechos Económicos, Sociales y Culturales (en lo adelante "Protocolo de San Salvador"), interpretados a la luz de los artículos 30 y 31 de la Convención de Viena sobre el Derecho de los Tratados".

76 Idem. No original: "ni por la Convención Americana, ni por el artículo 19.6 del Protocolo... interpretados a la luz de los artículos 30 y 31 de la Convención de Viena sobre el Derecho de los Tratados".

77 Ibidem, para. 7. 
CA. Contudo, parece haver algo ausente nas opiniões dos juízes: o fato de que a expansão dos direitos ambientais ocorreu no alargamento da opinião 23 e não apenas no litígio dos DESCA.

Se a Corte cita expressamente no caso Lhaka Honhat a OC-23/17 para fundamentar a expansão de direitos ambientais, direito à alimentação, à água, e de participação e identidade cultural, é interessante verificar que os juízes dissidentes negligenciam este argumento em sua dissidência. Eles não enfrentam o fato de que a Corte já decidira por sua justiciabilidade no passado e que porventura seria incongruente mudar essa posição em via contenciosa. Parece existir uma dissociação por parte dos magistrados que foi não apenas no âmbito contencioso, mas eminentemente através da jurisdição consultiva, que o principal alargamento dos DESCA ocorreu. ${ }^{78}$ Tal alargamento e aplicação contenciosa dos direitos desenvolvidos em âmbito consultivo obviamente possui desdobramentos e questionamentos.

A postura expansiva da Corte levanta uma série de interrogativos. Por exemplo, pode-se questionar se, à luz da nova interpretação da Corte, todos os direitos elencados no Pacto de San Salvador podem ser litigados diretamente sob a rubrica do artigo 26. A Corte também não esclarece se somente entidades coletivas como povos indígenas estariam legitimados a contestálos. Quais serão as reações dos Estados e dos atores sociais interamericanos diante dessa postura mais ampla da Corte? As decisões da Corte irão influenciar de alguma maneira em sua efetividade e no cumprimento das decisões? Estados estarão mais inclinados a resistir decisões baseadas no artigo 26 da Corte? As decisões baseadas nas interpretações de direitos sociais sob o artigo 26 ou postuladas por atores não originalmente reconhecidos serão tratadas de maneiras distintas pelos Estados e terão seus cumprimentos afetados? A prática futura oferecerá indicações para esses questionamentos, que influenciarão tanto os debates em relação à autoridade quanto de legitimidade da Corte.

78 Está sob deliberação uma opinião consultiva solicitada pela Comissão Interamericana de Direitos Humanos, acerca do "Alcance das obrigações dos Estados, no âmbito do Sistema Interamericano, sobre as garantias à liberdade sindical, sua relação com outros direitos e sua aplicação com uma perspectiva de gênero". Conforme explicitado, a liberdade sindical é um direito judicializável, conforme o artigo 19.6 do Protocolo de San Salvador. Assim, caso o parecer seja emitido, não ocorreria maior impacto sobre os contornos jurisdicionais da competência contenciosa da Corte e, portanto, somente em casos futuros seria identificável nova observação dos magistrados sobre a aplicação de uma mudança na jurisdição ter sido originada em uma OC. 


\section{PONTOS DE FORÇA, RISCOS E CONSEQUENCIAS DA EXPANSÃO DA CORTE EM VIA CONSULTIVA}

O exercício de expansão da jurisdição de uma corte internacional através de opiniões consultivas não é desprovido de desdobramentos, impactos e riscos. A imediata reação e divisão da Corte no caso Lhaka Honhat confirma essa tese. Nesta seção, três desses potenciais desdobramentos são explorados. O primeiro deles (I) são os pontos de força que tal exercício pode gerar em relação ao Sistema Interamericano de Direitos Humanos. O segundo desdobramento (II) é o potencial impacto da expansão da jurisdição da CtIDH em matéria de DESCA no que se refere ao controle de convencionalidade e, eventualmente, à aplicação dos critérios pela Comissão Interamericana de Direitos Humanos. O terceiro desdobramento (III) analisa os riscos de resistência à atitude expansiva da Corte e sua posterior recepção pelos Estados.

(I) Não se ignora que o exercício de expansão de jurisdição — que de uma maneira geral se insere numa tendência expansiva e protetiva da Cortepode possuir pontos positivos. O primeiro deles é o fato de que a Corte realiza algo que os Estados dificilmente realizarão num momento de resistência ao direito internacional: ${ }^{79}$ atribuir maior jurisdição a uma corte de direitos humanos num assunto de essencial interesse e de amplos contornos como o meio ambiente. Um exemplo bastante ilustrativo são as discussões envolvendo a Amazônia brasileira e a eventual responsabilização internacional do Brasil pelos alegados danos ocorridos em virtudes de incêndios. ${ }^{80}$ Dificilmente o atual governo brasileiro estaria inclinado a expandir a jurisdição da CtIDH aderindo expressamente à possibilidade de litigar questões ambientais. Obviamente que permanece o questionamento se o fato de que os Estados não adeririam não significa que a Corte está, efetivamente, evitando o consentimento dos Estados.

79 Parte da análise pode ser encontrada em Crawford, James, "The Current Political Discourse Concerning International Law”, The Modern Law Review, vol. 81, 2018, pp. 1-22; Pellet, Alain, "Values and Power Relations - The «Disillusionment» of International Law?", KFG Working Paper Series, núm. 34, maio de 2019; Koskenniemi, Martti, International Law and the Far Right: Reflections on Law and Cynicism, Haia, Asser Press, 2019; Krieger, Heike et al., The International Rule of Law: Rise or Decline?, Oxford, Oxford University Press, 2019.

80 Sobre a questão, ver Dupuy, Pierre-Marie, “Amazonie: le droit international en vigueur apporte des réponses substantielles”, Revista de Direito Internacional, vol. 16, 2019, pp. 2-6. 
Outro aspecto positivo do exercício da Corte é a realização de uma efetiva aplicação do artigo 26 dando concreto significado à ideia de "desenvolvimento progressivo": a lógica seria de que, vez que os Estados há quarenta anos entenderam que aquele ramo do direito deveria se desenvolver, uma série de movimentos e documentos internacionais legitimariam o agir da Corte ${ }^{81} \mathrm{Na}$ qualidade de um catalisador de novas tendências, o exercício da Corte estaria dando efeito útil a um dispositivo esquecido da Convenção e atualizando-o à luz do que há de mais inovador no direito internacional dos direitos humanos. Estaria a CtIDH enfim criando "condições que permitam a cada pessoa gozar dos seus direitos econômicos, sociais e culturais, bem como dos seus direitos civis e políticos". ${ }^{82} \mathrm{Ou}$, nas palavras da própria Corte, tal interpretação "permite atualizar o sentido dos direitos derivados da Carta que se encontram reconhecidos no artigo 26 da Convenção". ${ }^{83}$

Contudo, este movimento vanguardista protetivo da Corte dependerá essencialmente da vontade dos Estados para confirmar os dois argumentos positivos anteriormente solevados. Caso os Estados-parte da Convenção bem recepcionem os casos futuramente litigados em matéria ambiental e relativas a outros DESCA (como, e.g., o direito à água), o exercício da Corte se provará uma interessante técnica para inserir no seu rol de direitos protegidos também os direitos conexos ao meio ambiente. Um contexto de resistência à Corte Interamericana por parte de alguns países, sobretudo no âmbito

81 A ideia de desenvolvimento progressivo foi explorada melhor em sentenças posteriores ao caso Lagos del Campo vs. Peru, como no caso PobleteVilches y otros vs. Chile, em que declarou-se que a progressividade "no debe interpretarse en el sentido que, durante su periodo de implementación, dichas obligaciones se priven de contenido específico, lo cual tampoco implica que los Estados puedan aplazar indefinidamente la adopción de medidas para hacer efectivos los derechos en cuestión, máxime luego de casi cuarenta años de la entrada en vigor del tratado interamericano”. Corte IDH, Caso Poblete Vilches y otros vs. Chile. Mérito, reparações e custas, Sentença de 8 de março de 2018, Série C núm. 349, para. 104. Ainda, no caso Cuscul Pivaral y otros vs. Guatemala, a Corte reforçou que a progressividade deve ser entendida como proibição à inação e replicou o artigo 2.1 do Pacto Internacional de Direitos Econômicos, Sociais e Culturais, para apontar que o cumprimento desses direitos se deve realizar em conformidade com o máximo de recursos disponíveis. Corte IDH, Caso Cuscul Pivaral y otros vs. Guatemala..., cit., para. 80 .

82 Preâmbulo da Convenção Americana sobre Direitos Humanos.

83 Corte IDH, Caso Comunidades Indígenas Miembros de la Asociación Lhaka Honhat (Nuestra Tierra) vs. Argentina..., cit., para. 199. Do original: "la Corte realiza una interpretación que permite actualizar el sentido de los derechos derivados de la Carta que se encuentran reconocidos en el artículo 26 de la Convención”. 
Esta revista forma parte del acervo de la Biblioteca Jurídica Virtual del Instituto de Investigaciones Jurídicas de la UNAM

de suas cortes supremas, ${ }^{84}$ parece indicar que tal recepção não ocorrerá de maneira pacata tampouco uniformemente. Um argumento que favorece o argumento da Corte, inclusive indicado na opinião 23, é o fato de que a proteção do meio ambiente é comumente inserida no rol de direitos protegidos no âmbito das constituições latino-americanas. ${ }^{85} \mathrm{~A}$ Corte parece particularmente atenta em suas decisões a indicar as normas e as jurisprudências nacionais em relação ao direito litigado, num exercício muito similar (embora com distinções significativas) à técnica do "consenso europeu". ${ }^{86}$ Talvez, em vez de confirmar suas decisões nas decisões nacionais dos Estados, uma alternativa para atenuar os efeitos da expansão de sua jurisdição contenciosa através da consultiva é realizar uma maior indicação aos Estados quando tal situação ocorrer. Em situações extremas onde o próprio consentimento dos Estados pode estar em xeque (como litigar direitos não previstos na Convenção) uma consulta direta possa ser idealizada e seria bem-vinda.

(II) O segundo essencial desdobramento da expansão jurisdicional da Corte relaciona-se à exigência do controle de convencionalidade por parte dos poderes internos dos Estados membros da Convenção ${ }^{87}$ e a aplicação dos

84 Ver, nesse sentido: Huneeus, Alexandra Valeria, "Courts Resisting Courts: Lessons from the Inter-American Court's Struggle to Enforce Human Rights”, Cornell International Law Journal, vol. 44, 2011, pp. 493-533; Huneeus, Alexandra Valeria, "Rejecting the Inter-American Court", em Couso, Javier et al. (eds.), Cultures of Legality: Judicialization and Political Activism in Latin America, Cambridge, Cambridge University Press, 2010.

85 Corte IDH, OC-23/17, para. 58.

86 Lixinski, Lucas, "The Inter-American Court of Human Rights' Tentative Search for Latin American Consensus”, em Kapotas, Panos e Tzevelekos, Vassilis P. (eds.), Building Consensus on European Consensus: Judicial Interpretation of Human Rights in Europe and Beyond, Cambridge, Cambridge University Press, 2019. Sobre a questão, ver Dothan, Shai, "Judicial Deference Allows European Consensus to Emerge”, Chicago Journal of International Law, vol. 18, 2018 , pp. 392-418.

87 O controle de convencionalidade foi reconhecido em 2006, no caso Almonacid Arellano y otros vs. Chile (paras. 124 e ss.), embora essa sentença aponte que as bases de sua fundamentação possam ser traçadas desde o caso Barrios Altos vs. Peru (para. 43), de 2001. Na ocasião, a Corte entendeu que os juízes, enquanto parte do Estado que ratificou a Convenção, estão a ela submetidos e devem aplicá-la, juntamente com a interpretação dela feita pela Corte, nos casos concretos. Posteriormente, a Corte incorporou o dever de adoção por outros poderes estatais, declarando, por exemplo, no caso Masacre de Santo Domingo vs. Colômbia, de 2012, que "todas as autoridades e órgãos de um Estado Parte da Convenção tem obrigação de exercer um «controle de convencionalidade»" (para. 142). Burgorgue-Larsen (“El contexto...”, op. cit., p. 132) indica o papel do juiz Eduardo Ferrer Mac-Gregor no desenvolvimento teórico da doutrina, desde sua participação como juiz ad hoc mexicano no caso Cabrera García y Montiel Flores vs. México, 
Esta revista forma parte del acervo de la Biblioteca Jurídica Virtual del Instituto de Investigaciones Jurídicas de la UNAM

DESCA no âmbito da Comissão Interamericana. Um cenário que é agudizado pela função proto-constitucional que a CtIDH é atribuída. ${ }^{88}$ Desde a OC-21/14, a Corte Interamericana adota a posição de que o conteúdo de seus pareceres consultivos, enquanto norma interpretada, deve ser aplicado pelos Estados. ${ }^{89} \mathrm{~A}$ legitimidade dessa interpretação já esbarra em inúmeras críticas da doutrina ao controle, ${ }^{90}$ bem como de uma adoção díspar pelos membros do Sistema. ${ }^{91}$

de 2010. Sobre o desenvolvimento do controle, conferir Ramos, André de Carvalho, "Control of Conventionality and the Struggle to Achieve a Definitive Interpretation of Human Rights: The Brazilian Experience", Revista del Instituto Interamericano de Derechos Humanos, vol. 64, 2016, pp. 11-32; Burgorgue-Larsen, Laurence, "Conventionality Control: Inter-American Court of Human Rights (IACtHR)”, Max Planck Encyclopedia of Procedural International Law, 2018.

88 Ver, nesse sentido: Von Bogdandy, Armin, "Ius constitutionale commune na América Latina. Uma reflexão sobre um constitucionalismo transformador", Revista de Direito Administrativo, vol. 269, 2015, pp. 13-66; Huneeus, Alexandra Valeria, "The Inter-American Court of Human Rights: How Constitutional Lawyers Shape Court Authority”, em Alter, Karen J. et al. (eds.), International Court Authority, Oxford, Oxford University Press, 2018.

89 Corte IDH, OC-21/14, paras. 31 e 32. O argumento utilizado pela Corte para integrar o conteúdo dos pareceres ao escopo de interpretações a se incorporar no âmbito interno foi de que a competência consultiva "inegavelmente compartilha com sua competência contenciosa o propósito do Sistema Interamericano de Direitos Humanos de «proteção dos direitos fundamentais dos seres humanos»”, em referência ao para. 29 da OC-2/82.

90 Quanto a críticas à fundamentação usada pela Corte para criar a doutrina do controle de convencionalidade, pela impossibilidade de vinculação, além de uma avaliação sobre a possibilidade de emplaca-la via construção de um costume, todavia longe de estar concretizado nos países do Sistema, conferir Contesse, Jorge, "The International Authority of the Inter-American Court of Human Rights: A Critique of the Conventionality Control Doctrine”, The International Journal of Human Rights, vol. 22, 2018, pp. 1169-1191. Mais críticas em: Mejía-Lemos, Diego Germán, "On the «Control de Convencionalidad» Doctrine: A Critical Appraisal of the Inter-American Court of Human Rights' Relevant Case Law", Anuario Mexicano de Derecho Internacional, vol. XIV, 2014, pp. 117-151.

91 Inúmeros estudos tratam da recepção da doutrina do controle de convencionalidade no continente. Burgorgue-Larsen ("El contexto...”, op. cit., p. 133-135) aponta, em geral, a incorporação realizada pelo México, e em oposição as práticas, à época, de Venezuela e Brasil, além de apontar perigos de interpretações errôneas, que seria o caso do Uruguai. Para um estudo mais específico sobre a adesão brasileira, conferir Volpini Silva, Carla Ribeiro e Wanderley Junior, Bruno, "A responsabilidade internacional do Brasil em face do controle de convencionalidade em sede de direitos humanos: conflito de interpretação entre a jurisdição da Corte Interamericana de Direitos Humanos e o Supremo Tribunal Federal quanto a Lei de Anistia”, Revista de Direito Internacional, vol. 12, pp. 612-630. Já uma análise sistêmica recente está contida em Legale, Siddharta, A Corte Interamericana de Direitos Humanos como tribunal constitucional transnacional, Rio de Janeiro, Lumen Juris, 2019. 
Particularmente à OC-23/17, depreende-se que os Estados deverão incorporar todas as noções ambientais desenvolvidas progressivamente no âmbito da Corte. Isso pode gerar discrepâncias entre direitos ambientais e outros direitos, ponderações comumente realizadas no âmbito das supremas cortes de acordo com os interesses das agendas dos governos. No mais, ainda que se alegue que os sistemas internos possuem normas relativas à proteção do meio ambiente, os critérios adotados e princípios reconhecidos no parecer apresentam um avanço em relação ao próprio direito internacional ambiental, como o critério de extraterritorialidade, o que poderia suplantar o procedimento legislativo interno, ${ }^{92}$ a determinação de políticas públicas e o diálogo sócio-político denso acerca dessa temática ainda em desenvolvimento. ${ }^{93}$

92 Criticou-se a liberdade limitada dos juízes nacionais ao aplicarem obrigatoriamente a jurisprudência interamericana para exercer o controle difuso de constitucionalidade, pois eles possuem maior conhecimento sobre a realidade local e, nesse sentido, uma aplicação mecânica poderia até afetar a independência de suas ponderações. Dulitzky, Ariel E., "An Alternative Approach to the Conventionality Control Doctrine”, AJIL Unbound, vol. 109, 2015, pp. 100108. Isso parece ser reforçado por análises recentes, como o projeto do Comitê Jurídico Interamericano de elaboração de um guia para a aplicação do princípio de convencionalidade, em condução pela relatora Dra. Ruth Stella Correa Palacio. Em 2018 foi apresentado o texto do guia, que continha a determinação, dentre outros, do "princípio quarto", que descreve a predominância das normas internacionais. CJI, Guía para la aplicación del principio de convencionalidad, CJI/doc.557/18, 20 de fevereiro de 2018, disponível em: http://www.oas.org/es/sla/cji/docs /CJI_doc_557-18.pdf.

93 Os movimentos de desenvolvimento sociais, políticos, econômicos e culturais pelos quais passam os sistemas internos e internacionais possuem impactos na atividade de uma Corte Internacional (CI). Essa temática inerente à resistência a CIs aparenta se apresentar, de certa forma, mais bem-sucedida quanto à OC-24/17, vez que as questões de direitos associados à identidade de gênero passavam por discussões internas nos países do continente e foram relativamente bem recebidas. Traça-se isso desde o acolhimento chileno das determinações do caso Atala Riffo y niñas vs. Chile, conforme indica Burgorgue-Larsen (“El contexto...”, op. cit., pp. 138 e 139), até a incorporação do direito à retificação de nome por cortes supremas, como a costa-riquense, país que originou a consulta, e a brasileira, cujo voto-vogal que determinou o julgamento do Supremo Tribunal Federal brasileiro na Ação Direta de Inconstitucionalidade 4.275/DF conteve uma referência expressa à OC-24/17 (disponível em: http://www.stf.jus. $\mathrm{br} /$ arquivo/cms/noticiaNoticiaStf/anexo/ADI4275VotoGMTransgneros.pdf). Por outro lado, o próprio não cumprimento de decisões que abordavam direitos ambientais ligados a povos indígenas aponta certa resistência dos Estados. A exemplo, no relatório "Situación de los derechos humanos de los pueblos indígenas y tribales de la Panamazonía”, de 2019, a Comissão Interamericana identificou, quanto ao caso Pueblo Indígena Kichwa de Sarayaku vs. Equador, cuja sentença data de 2012, informações recebidas de que não somente o Estado promoveu remoção ínfima 
Esta revista forma parte del acervo de la Biblioteca Jurídica Virtual del Instituto de Investigaciones Jurídicas de la UNAM

A especificidade de aplicação do controle de convencionalidade às disposições contidas em opiniões consultivas diz respeito ao modo como direitos, princípios e critérios são nelas reconhecidos. $\mathrm{O}$ fato de não estarem atreladas a um caso específico pode gerar a discussão de normas de maneira abstrata, que resultam em conceitos vagos e com difícil aplicação, por exemplo, aos julgamentos concretos, a exemplo da noção de controle efetivo não definida na OC-23/17. Em igual sentido, a possibilidade de se apontar "políticas públicas", também sem maior detalhamento de sua aplicabilidade e avaliação material de sua execução caso a caso, já foi alegada como violadora do princípio da subsidiariedade ${ }^{94} \mathrm{e}$ coloca diversos problemas práticos caso se queira exigir da Corte um julgamento sobre a não implementação das recomendações das OCs por algum Estado que reconhece sua competência.

Problema similar se verificaria no âmbito da aplicação dos parâmetros desenvolvidos pela Corte em relação aos DESCA no contencioso da Comissão Interamericana de Direitos Humanos. Enquanto órgão quase-judicial, muito do exercício evolutivo no sistema se origina de sugestões feitas por suas relatorias, como a REDESCA e da decisão quanto ao encaminhamento de um caso à Corte. ${ }^{95}$ Ainda, no processamento de petições, aplicam-se as intepretações da Corte realizadas, inclusive, em sede consultiva, como a OC-21/14 apontou após a discussão do controle de convencionalidade. ${ }^{96}$

da quantidade de explosivos utilizados pela indústria petroleira deixados no território do povo, como estabeleceu uma nova concessão para exploração de petróleo, que afetaria $91 \%$ do espaço por eles ocupados (para. 89). Já a Corte, em supervisão e cumprimento de sentença de 2018, referente ao caso del Pueblo Saramaka vs. Suriname, de 2007, reconheceu que o Suriname não realizou as demarcações de terra e autorizou uma nova concessão sem realizar estudos de impacto ambiental na região (para. 28).

94 Candia Falcón, Gonzalo, op. cit., pp. 59, 67, 72 e 73. O autor esclarece que alguns critérios limitadores da jurisdição consultiva, como a não utilização para interferência em debates políticos internos, se baseia no princípio de subsidiariedade do sistema, que determina o recurso ao sistema somente quando os Estados não são capazes de garantir os direitos reconhecidos nos tratados, por erro, negligência ou infração direta. Assim, emitir pareceres de alcance genérico que especificam políticas públicas (em referência às OCs 16/99, 17/02, 18/03, 21 / 14 e $24 / 17)$, interferiria na definição da agenda dos governantes internos, que possuem certa margem de apreciação no estabelecimento das políticas a partir dos direitos contidos nos tratados. Ele referencia a dissidência do juiz Oliver Jackman, que sugeria a inadmissão da OC-17/02, por considerar a demanda uma especulação puramente acadêmica, sem justificativa numa urgência pública ou questão jurídica complexa, o que ultrapassaria o caráter essencialmente judicial da Corte (para. 2 do Voto).

95 Artigo 45.2.c. da Regulamento da Comissão Interamericana de Direitos Humanos.

96 Corte IDH, OC-21/14, para. 32. 
Assim, a possibilidade de se contestar essas mudanças no contexto da Comissão é pequeno.

(III) O terceiro desdobramento que a atividade de expansão jurisdicional da Corte envolve o impacto geral na legitimidade e autoridade da Corte em relação aos Estados e demais atores sociais do sistema interamericano.

Estudos recentes propõem-se a analisar a importância e os elementos que contribuem ou não para a autoridade e legitimidade de cortes internacionais e também da Corte Interamericana. ${ }^{97}$ Se a legitimidade pode ser descrita, para se empregar o célebre conceito de Thomas Franck, como um "impulsionar na direção do cumprimento", ${ }^{98}$ diversas são as forças da Corte Interamericana que podem reforçar a sua legitimidade. Em síntese, a legitimidade de uma corte internacional pode advir de diversas fontes: normativas, sociológicas, políticas. Ela pode ser também influenciada pela percepção de seus clientes de que seus julgamentos são bem fundamentados ou que operam de modo balanceado de acordo com as expectativas dos atores sociais envolvidos. Como observou o juiz Manrique em seu voto no caso Lhaka Honhat, "é importante considerar que a legitimidade do Tribunal se funda na solidez de seus raciocínios e em seu apego ao direito e à prudência de suas decisões". ${ }^{99}$ Também os juízes Sierra Porto e Vio Grossi se preocuparam com os impac-

97 Ver, por exemplo, Becerra Ramírez, Manuel, La Corte Interamericana de Derechos Humanos a veinticinco años de su funcionamento, Cidade do México, UNAM, 2007; Engstrom, Par, "Reconceptualising the Impact of the Inter-American Human Rights System”, Revista Direito e Práxis, vol. 8, 2017, pp. 1250-1285.

98 Franck, Thomas M., The Power of Legitimacy Among Nations, Nova Iorque-Oxford, Oxford University Press, 1990, p. 24: "Legitimacy is a property of a rule or rulemaking institution which itself exerts a pull toward compliance on those addressed normatively because those addressed believe that the rule or institution has come into being and operates in accordance with generally accepted principles of right process". Sobre a questão, ver Treves, Tullio, "Aspects of Legitimacy of Decisions of International Courts and Tribunals", em Wolfrum, Rüdiger e Röben, Volker (eds.), Legitimacy in International Law, Basel, Springer, 2008; Bodansky, Daniel, "Legitimacy in International Law and International Relations", em Dunoff, Jeffrey L. e Pollack, Mark A. (eds.), Interdisciplinary Perspectives on International Law and International Relations: The State of the Art, Cambridge, Cambridge University Press, 2012; Grossman, Nienke et al. (eds.), Legitimacy and International Courts, Cambridge, Cambridge University Press, 2018; Howse, Robert et al. (eds.), The Legitimacy of International Trade Courts and Tribunals, Cambridge, Cambridge University Press, 2018; e, de maneira geral, Franck, Thomas M., op. cit.

99 Corte IDH, Caso Comunidades Indígenas Miembros de la Asociación Lhaka Honhat (Nuestra Tierra) vs. Argentina, Voto parcialmente dissidente do juiz Ricardo C. Pérez Manrique, para. 16. Do original: "Es importante considerar que la legitimidad del Tribunal se funda en la solidez de sus razonamientos y en su apego al derecho y la prudencia de sus fallos”. 
tos e ondulações causadas pela estratégia da Corte em relação aos DESCA em sua legitimidade.

Não é somente a capacidade de convencimento em relação ao direito e a fundamentação de uma decisão que influencia a legitimidade de uma corte internacional. A assim chamada legitimidade normativa é talvez uma das mais cardinais por lidar exatamente com o consentimento dos Estados. Cuida-se da legitimidade que verifica se uma corte age no interior da moldura que lhe foi desenhada, a qual pode ser enfraquecida caso a corte ultrapasse os limites dos poderes normativamente atribuídos a ela. Isso pode afetar seus clientes e o número de Estados parte do sistema, bem como desestimular a adesão de outros Estados que ainda não aceitam a jurisdição da Corte Interamericana. ${ }^{100} \mathrm{O}$ fato de que a Corte expandiu sua jurisdição admitindo a justiciabilidade dos DESCA através de opiniões consultivas sem uma ampla participação dos Estados não reforça sua legitimidade, antes pelo contrário.

A expansão da jurisdição contenciosa (em atores peticionantes, matérias litigáveis não previstas na Convenção e direitos não previstos anteriormente) através da consultiva pode oferecer resistência por parte de atores sociais envolvidos no processo jurídico interamericano e sensibilizar a legitimidade da Corte Interamericana de Direitos Humanos. Se a Corte oferecer a impressão que está se atribuindo poderes tergiversando o consentimento dos Estados, é possível que haja por parte dos Estados reações relativas tanto ao cumprimento quanto à própria autoridade da Corte, podendo inclusive afetar a sua membresia. Tais reações podem afetar a missão principal da Corte que é a de proteger direitos humanos.

Isso não significa que a Corte não tenha alternativas para mitigar eventuais problemas de legitimidade sem necessariamente revisar seu posicionamento de justiciabilidade dos DESCA ou das expansões desenvolvidas até o presente momento. Uma posição mais cautelosa e com maior diálogo com os Estados em relação aos avanços da jurisdição contenciosa e suas potencialidades parece ser uma saída intermediária possível. Uma melhor ponderação em

100 Esse argumento foi utilizado no voto do juiz Vio Grossi, para. 96: "Finalmente, es imperioso repetir que, de insistirse en el derrotero adoptado por la Sentencia, el Sistema Interamericano de Derechos Humanos en su conjunto podría verse seriamente limitado. Y ello en razón de que muy probablemente, por una parte, no se incentivaría, sino todo lo contrario, la adhesión de nuevos Estados a la Convención ni la aceptación de la competencia contenciosa de la Corte por los que no lo hayan hecho y por la otra parte, podría renovarse o aún acentuarse la tendencia entre los Estados Partes de la Convención de no dar cumplimiento completo y oportuno a sus fallos". 
relação aos efeitos das opiniões consultivas no contencioso indica a garantia tanto da missão da Corte de proteger direitos humanos no continente americano quanto a garantia dos Estados de que eles enfrentarão um contencioso nos limites de seu aceite da jurisdição.

\section{CONCLUSÕES}

A função consultiva em cortes internacionais foi originalmente pensada como um exercício não judicial para oferecer opiniões que esclareçam ou identifiquem questões jurídicas, comumente ligadas a temáticas controversas. Contudo, o limite entre declarar um direito existente, desenvolver direitos e lawmaking é inexato e, por isso, o significado da força e natureza dos pareceres consultivos permanece incerto. ${ }^{101}$ Em não poucas ocasiões na história do contencioso internacional opiniões consultivas serviram para tangenciar levemente o consentimento dos Estados. A Corte Interamericana de Direitos Humanos no passado utilizou-se estrategicamente de seus poderes consultivos para expandir o alcance protetivo de sua jurisdição. As consequências das recentes escolhas da Corte de, através da via consultiva, expandir sua jurisdição em questões envolvendo DESCA e permitindo o litígio estratégico de questões ambientais estão ainda para se descortinar.

Esse novo comportamento no âmbito consultivo em análise dos direitos materiais da $\mathrm{CADH}$ se deflagrou em um contexto cujo arquipélago de fatores também recentes solevam diversas questões passíveis de impactar a legitimidade do órgão. Dentre eles têm-se as discussões sobre a judicialização dos DESCA (direitos econômicos, sociais, culturais e - agora - ambientais), a adjudicação deles com base somente no artigo 26 da Convenção, o questionamento da doutrina do controle de convencionalidade, o movimento na Corte de retração da interpretação evolutiva. Em virtude de todos esses fatores, defende-se que a Corte deve proceder com maior moderação ao expandir seus poderes através da via consultiva.

A resposta dos Estados às possíveis decisões condenatórias, medidas provisórias e demais impactos na gestão de suas ações domésticas, ${ }^{102}$ em exer-

101 Oellers-Frahm, Karin, “Lawmaking...”, op. cit., pp. 1033 e 1046.

102 Sobre a questão, ver Becerra Ramírez, Manuel, La recepción del derecho internacional en el derecho interno, Cidade do México, UNAM, 2006. 
cício desses novos contornos da jurisdição contenciosa, será essencial para avaliar os rumos das discussões atualmente muito contidas na Corte Interamericana, principalmente para o exercício da sua tradicionalmente celebrada ampla competência consultiva.

No primeiro caso de judicialização de direitos ESCA, o juiz Sierra Porto rememorou que "somente a crítica sincera e o debate aberto e público podem ajudar a mitigar, até certo ponto, os riscos de legitimidade e insegurança jurídica que podem se desprender dessa sentença”. ${ }^{103}$ Como verificado, a estratégia de expandir a jurisdição da Corte através de sua função consultiva comporta riscos. Seria interessante se a Corte estivesse atenta às vozes da sociedade civil, mas também dos Estados em relação a essa expansão de jurisdição, promovendo maior cautela e diálogo nesse exercício. Dados os contornos flexíveis e um tanto quanto discricionários da atividade consultiva, é uma questão de política judiciária escolher quais são os campos que vale a pena avançar no corpus iuris de direitos humanos. A divisão no interior da Corte no caso Lhaka Honhat demonstra que certas questões ainda não são unanimidade nem mesmo no interior da Corte.

As reações futuras dos Estados provarão se a política judiciária da Corte Interamericana de litigar direitos econômicos, sociais, culturais e ambientais foi uma boa estratégia. Verdade é que, para parafrasear a célebre expressão de Bruno Simma, o gênio dos DESCA escapou da lâmpada na jurisprudência da Corte Interamericana. ${ }^{104} \mathrm{Em}$ vez de tentar comprimi-lo de volta, a Corte pode ter a ocasião, também em via consultiva, de modelar a sua expansão.

\section{BIBLIOGRAFIA}

ALTER, Karen J. et al. (eds.), International Court Authority, Oxford, Oxford University Press, 2018.

ASTA, Gabriele, La funzione consultiva delle Corti Regionali dei Diritti Umani, Nápoles, Scientifica, 2019.

103 Corte IDH, Caso Lagos del Campo vs. Peru, Voto parcialmente dissidente do juiz Humberto Antonio Sierra Porto, para. 49. Do original: "Solo la crítica sincera y el debate abierto y público puede ayudar a mitigar, hasta cierto punto, los riesgos de legitimidad y de inseguridad jurídica que se puedan desprender de esta Sentencia”.

104 Simma, Bruno, "Mainstreaming Human Rights: The Contribution of the International Court of Justice”, Journal of International Dispute Settlement, vol. 3, 2012, pp. 7-29. 
BAILliet, Cecilia M., "The Strategic Prudence of the Inter-American Court of Human Rights: Rejection of Requests for an Advisory Opinion”, Revista de Direito Internacional, vol. 15, 2018.

BeCERra RamíreZ, Manuel, La Corte Interamericana de Derechos Humanos a veinticinco años de su funcionamento, Cidade do México, UNAM, 2007.

BECERRA RAmíreZ, Manuel, La recepción del derecho internacional en el derecho interno, Cidade do México, UNAM, 2006.

BEnZ, Eleanor, “The Inter-American Court's Advisory Function Continues to Boom - A Few Comments on the Requests Currently Pending", EJIL: Talk!, 25 de novembro de 2019.

BODANSKY, Daniel, "Legitimacy in International Law and International Relations”, em DunOFF, Jeffrey L. e POLlaCk, Mark A. (eds.), Interdisciplinary Perspectives on International Law and International Relations: The State of the Art, Cambridge, Cambridge University Press, 2012.

Bonafé, Beatrice I. e PAlChetTI, Paolo, "Relying on General Principles in International Law”, em BRÖLMANN, Catherine e RADI, Yannick, Research Handbook on the Theory and Practice of International Lawmaking, Cheltenham, Elgar Publishing, 2016.

BOYLE, Alan, "Human Rights and the Environment", em BOER, Ben, Environmental Law Dimensions of Human Rights, Oxford, Oxford University Press, 2015.

Buergenthal, Thomas, "The Advisory Practice of the Inter-American Human Rights Court”, American Journal of International Law, vol. 79, 1985.

Burgorgue-LARSEN, Laurence, "Conventionality Control: Inter-American Court of Human Rights (IACtHR)”, Max Planck Encyclopedia of Procedural International Law, 2018.

BurgORGUE-LARSEN, Laurence, “«Decompartmentalization»: The Key Technique for Interpreting Regional Human Rights Treaties”, International Journal of Constitutional Law, vol. 16, 2018.

Burgorgue-LARSEN, Laurence, "El contexto, las técnicas y las consecuencias de la interpretación de la Convención Americana de los Derechos Humanos", Estudios Constitucionales, ano 12, núm. 1, 2014.

CAnÇADO TRINDAdE, Antônio Augusto, "Os tribunais internacionais contemporâneos e a busca da realização do ideal da justiça internacional", Revista da Faculdade de Direito da UFMG, vol. 57, 2010.

CAnÇAdo Trindade, Antônio Augusto, "The Humanization of Consular Law: The Impact of Advisory Opinion No. 16 (1999) of the Inter-Ame- 
rican Court of Human Rights on International Case-Law and Practice”, Chinese Journal of International Law, vol. 6, 2007.

CANDia FalCón, Gonzalo, "Causales de inadmisibilidad de opiniones consultivas: reforzando el carácter subsidiario del sistema interamericano de derechos humanos", Revista Chilena de Derecho, vol. 45, 2018.

CASSESE, Antonio, I diritti umani nel mondo contemporaneo, Roma, Laterza, 1988.

CONTESSE, Jorge, "The International Authority of the Inter-American Court of Human Rights: A Critique of the Conventionality Control Doctrine", The International Journal of Human Rights, vol. 22, 2018.

CosTA, Pietro, "Dai diritti naturali ai diritti umani: episodi di retorica universalistica”, em MeCCARELLI, Massimo et al. (orgs.), Il lato oscuro dei diritti umani, Madrid, Universidad Carlos III de Madrid, 2014.

CRAWFORD, James, "The Current Political Discourse Concerning International Law", The Modern Law Review, vol. 81, 2018.

D'ASPREMONT, Jean, Formalism and the Sources of International Law: A Theory of the Ascertainment of Legal Rules, Oxford, Oxford University Press, 2011.

De Brabandere, Eric, "The Use of Precedent and External Case Law by the International Court of Justice and the International Tribunal for the Law of the Sea", The Law and Practice of International Courts and Tribunals, vol. 15, 2016.

Dothan, Shai, "Judicial Deference Allows European Consensus to Emerge", Chicago Journal of International Law, vol. 18, 2018.

DulitZKY, Ariel E., "An Alternative Approach to the Conventionality Control Doctrine", AJIL Unbound, vol. 109, 2015.

DupuY, Pierre-Marie, "Amazonie: le droit international en vigueur apporte des réponses substantielles”, Revista de Direito Internacional, vol. 16, 2019.

ENGSTROM, Par, "Reconceptualising the Impact of the Inter-American Human Rights System”, Revista Direito e Práxis, vol. 8, 2017.

EsTUPIÑAn SILVA, Rosmerlin, "Primera opinión interamericana sobre medio ambiente: ¿derecho exigible o decisión ultra vires?”, Criterio Jurídico Garantista, vol. 11.

Franck, Thomas M., The Power of Legitimacy Among Nations, Nova IorqueOxford, Oxford University Press, 1990.

Frowein, Jochen e Oellers-Frahm, Karin, “Article 65”, em Zimmermann, Andreas et al. (orgs.), The Statute of the International Court of Justice: A Commentary, Oxford, Oxford University Press, 2012. 
Gordon Lauren, Paul, "The Foundations of Justice and Human Rights in Early Legal Texts and Thought”, em SHELTON, Dinah, The Foundations of Justice and Human Rights in Early Legal Texts and Thought, Oxford, Oxford University Press, 2013.

Grossman, Nienke et al. (eds.), Legitimacy and International Courts, Cambridge, Cambridge University Press, 2018.

Guillaume, Gilbert, "The Use of Precedent by International Judges and Arbitrators", Journal of International Dispute Settlement, vol. 2, 2011.

Howse, Robert et al. (eds.), The Legitimacy of International Trade Courts and Tribunals, Cambridge, Cambridge University Press, 2018.

Huneeus, Alexandra Valeria, "Courts Resisting Courts: Lessons from the Inter-American Court's Struggle to Enforce Human Rights”, Cornell International Law Journal, vol. 44, 2011.

HuneEus, Alexandra Valeria, "Rejecting the Inter-American Court", em Couso, Javier et al. (eds.), Cultures of Legality: Judicialization and Political Activism in Latin America, Cambridge, Cambridge University Press, 2010. HuneEus, Alexandra Valeria, "The Inter-American Court of Human Rights: How Constitutional Lawyers Shape Court Authority”, em Alter, Karen J. et al. (eds.), International Court Authority, Oxford, Oxford University Press, 2018.

Huneeus, Alexandra Valeria e Madsen, Mikael Rask, "Between Universalism and Regional Law and Politics: A Comparative History of the American, European, and African Human Rights Systems", International Journal of Constitutional Law, vol. 16, 2018.

HunT, Lynn, Inventing Human Rights: A History, Nova Iorque, W.W. Norton \& Company, 2008.

Kelly, Elsa, "The Precautionary Approach in the Advisory Opinion Concerning the Responsibilities and Obligations of States Sponsoring Persons and Entities with Respect to Activities in the Area", em InTERnATIONAL TRIBUNAL FOR THE LAW OF THE SEA, The Contribution of the International Tribunal for the Law of the Sea to the Rule of Law: 1996-2016, Leiden, Brill, 2017. KILLANDER, Magnus, "Interpreting Regional Human Rights Treaties", Revista Sur, vol. 13, 2010.

Koskenniemi, Martti, International Law and the Far Right: Reflections on Law and Cynicism, Haia, Asser Press, 2019.

KRIEGER, Heike et al., The International Rule of Law: Rise or Decline?, Oxford, Oxford University Press, 2019. 
Esta revista forma parte del acervo de la Biblioteca Jurídica Virtual del Instituto de Investigaciones Jurídicas de la UNAM

LAUTERPACHT, Hersch, The Development of International Law by the International Court, Londres, Stevens \& Sons, Ltd. (Nova Iorque, Frederick A. Prager, 1958).

LEgale, Siddharta, A Corte Interamericana de Direitos Humanos como tribunal constitucional transnacional, Rio de Janeiro, Lumen Juris, 2019.

LimA, Lucas Carlos, "A opinião sobre o arquipélago de Chagos: a jurisdição consultiva da Corte Internacional de Justiça e a noção de controvérsia", Revista da Faculdade de Direito da Universidade Federal de Minas Gerais, núm. 75, 2019.

LimA, Lucas Carlos, “As decisões da Corte Internacional de Justiça como elemento de desenvolvimento do direito internacional”, em DAL RI JUNIOR, Arno e MOURA, Aline Beltrame de (orgs.), Jurisdição internacional: interação, fragmentação, obrigatoriedade, Ijuí, Unijuí, 2014.

Lima, Lucas Carlos, $O$ uso autoritativo das decisões judiciais internacionais pela Corte Internacional de Justiça: precedente e judicial lawmaking do direito internacional (dissertação mestrado), Florianópolis, Universidade Federal de Santa Catarina, Centro de Ciências Jurídicas, Programa de Pós-Graduação em Direito, 2013.

LimA, Lucas Carlos, “O uso de experts em controvérsias ambientais perante a Corte Internacional de Justiça”, Revista de Direito Internacional, vol. 13, 2016.

LIXINSKI, Lucas, “The Inter-American Court of Human Rights' Tentative Search for Latin American Consensus", em Kapotas, Panos e TzEVELEKOS, Vassilis P. (eds.), Building Consensus on European Consensus: Judicial Interpretation of Human Rights in Europe and Beyond, Cambridge, Cambridge University Press, 2019.

LIXINSKI, Lucas, "Treaty Interpretation by the Inter-American Court of Human Rights: Expansionism at the Service of the Unity of International Law”, European Journal of International Law, vol. 21, 2010.

LYON, Beth, "The Inter-American Court of Human Rights Defines Unauthorized Migrant Worker's Rights for the Hemisphere: A Comment on Advisory Opinion 18", New York University Review of Law and Social Change, vol. 28, 2004.

MADSEN, Mikael Rask et al., "Backlash against International Courts: Explaining the Forms and Patterns of Resistance to International Courts", International Journal of Law in Context, núm. especial 2, 2018. 
MejíA-Lemos, Diego Germán, "On the «Control de Convencionalidad» Doctrine: A Critical Appraisal of the Inter-American Court of Human Rights' Relevant Case Law", Anuario Mexicano de Derecho Internacional, vol. XIV, 2014.

Neuman, Gerald L., "Import, Export and Regional Consent in the InterAmerican Court of Human Rights", European Journal of International Law, vol. 19, 2008.

NikKen, Pedro, "La función consultiva de la Corte Interamericana de Derechos Humanos", em CORTE IDH, Memoria del Seminario "El sistema interamericano de protección de derechos humanos en el umbral del siglo XXI", San José, Corte Interamericana de Direitos Humanos, 2003, t. I.

Oellers-Frahm, Karin, "Article 96 Un Charter”, em Zimmermann, Andreas et al. (orgs.), The Statute of the International Court of Justice: A Commentary, Oxford, Oxford University Press, 2012.

Oellers-Frahm, Karin, "Lawmaking Through Advisory Opinions?”, German Law Journal, vol. 12, 2011.

PaPANTONIOU, Angeliki, “Advisory Opinion on the Environment and Human Rights", American Journal of International Law, vol. 112, 2018.

PAVONI, Riccardo, "Environmental Jurisprudence of the European and Inter-American Courts of Human Rights”, em BoER, Ben, Environmental Law Dimensions of Human Rights, Oxford, Oxford University Press, 2015. PAVONI, Riccardo, Interesse pubblico e diritti individuali nella giruisprudenza ambientale della Corte Europea dei Diritti Umani, Nápoles, Scientifica, 2013.

PELlET, Alain, "Decisions of the ICJ as Sources of International Law?", Gaetano Morelli Lectures Series, vol. 2, 2018.

PELLET, Alain, "Values and Power Relations - The «Disillusionment» of International Law?”, KFG Working Paper Series, núm. 34, maio de 2019.

Pellet, Alain e Muller, Daniel, “Article 38”, em Zimmermann, Andreas et al. (orgs.), The Statute of the International Court of Justice: A Commentary, Oxford, Oxford University Press, 2012.

PINTO, Mónica, Las fuentes del derecho internacional en la era de la globalización, Buenos Aires, Eudeba, 2010.

Ramos, André de Carvalho, "Control of Conventionality and the Struggle to Achieve a Definitive Interpretation of Human Rights: The Brazilian Experience", Revista del Instituto Interamericano de Derechos Humanos, vol. 64, 2016. 
ROA, Jorge Ernesto, La función consultiva de la Corte Interamericana de Derechos Humanos, Bogotá, Universidad Externado de Colombia-Instituto de Estudios Constitucionales, 2015.

Ruiz-Chiriboga, Oswaldo R., "The American Convention and the Protocol of San Salvador: Two Intertwined Treaties: Non-Enforceability of Economic, Social and Cultural Rights in the Inter-American System”, Netherlands Quarterly of Human Rights, vol. 31, 2013.

SCHMID, Julie Calidonio, "Advisory Opinions on Human Rights: Moving Beyond a Pyrrhic Victory", Duke Journal of Comparative \& International Law, vol. 16, 2006.

SHELTON, Dinah, "Human Rights and the Environment: Substantive Rights", em Fitzmaurice, Malgosia et al. (eds.), Research Handbook on International Environmental Law, Cheltenham, Edward Elgar Publishing, 2010.

SimmA, Bruno, "Mainstreaming Human Rights: The Contribution of the International Court of Justice", Journal of International Dispute Settlement, vol. 3, 2012.

TAMS, Christian J., "The Development of International Law by the International Court of Justice", Gaetano Morelli Lectures Series, vol. 2, 2018.

ThiRlway, Hugh, "The Law and Procedure of the International Court of Justice 1960-1989: Part Nine”, British Yearbook of International Law, vol. 69, 1998.

THIRLWAY, Hugh, The Sources of International Law, 2a. ed., Oxford, Oxford University Press, 2019.

TREVES, Tullio, "Aspects of Legitimacy of Decisions of International Courts and Tribunals”, em Wolfrum, Rüdiger e RÖBEN, Volker (eds.), Legitimacy in International Law, Basel, Springer, 2008.

Treves, Tullio, "The Expansion of International Law. General Course on Public International Law", Collected Courses of the Hague Academy of International Law, vol. 398, 2015.

VANNESTE, Frédéric, "Interpréter la Convention européenne des droits de l'homme et la Convention américaine des droits de l'homme: comment réconcilier les pratiques divergentes avec la théorie générale”, Revue québécoise de droit international, 2016.

VIVES, Francisco Pascual, "Consenso e interpretación evolutiva de los tratados regionales de derechos humanos", Revista Española de Derecho Internacional, vol. LXVI, 2014. 
Esta revista forma parte del acervo de la Biblioteca Jurídica Virtual del Instituto de Investigaciones Jurídicas de la UNAM

VolPini Silva, Carla Ribeiro e Wanderley Junior, Bruno, "A responsabilidade internacional do Brasil em face do controle de convencionalidade em sede de direitos humanos: conflito de interpretação entre a jurisdição da Corte Interamericana de Direitos Humanos e o Supremo Tribunal Federal quanto a Lei de Anistia", Revista de Direito Internacional, vol. 12.

VON BOGDANDY, Armin, "Ius constitutionale commune na América Latina. Uma reflexão sobre um constitucionalismo transformador", Revista de Direito Administrativo, vol. 269, 2015.

Von Bogdandy, Armin e VenZKe, Ingo, InWhose Name?: A Public Law Theory of International Adjudication, Oxford, Oxford University Press, 2014. 